\title{
A STUDY OF LIQUID SCINTILLATOR AND FIBER MATERIALS \\ FOR USE IN A FIBER CALORIMETER
}

by

PETER PARKER ALTICE, JR.

APRIL 1990

\section{DISCLAIMER}

This report was prepared as an account of work sponsored by an agency of the United States Government. Neither the United States Government nor any agency thereof, nor any of their employees, makes any warranty, express or implied, or assumes any legal liability or responsibility for the accuracy, completeness, or usefulness of any information, apparatus, product, or process disclosed, or represents that its use would not infringe privately owned rights. Reference herein to any specific commercial product, process, or service by trade name, trademark, manufacturer, or otherwise does not necessarily constitute or imply its endorsement, recommendation, or favoring by the United States Government or any agency thereof. The views and opinions of authors expressed herein do not necessarily state or reflect those of the United States Government or any agency thereof.

Rengiven! in:

NOV 301990

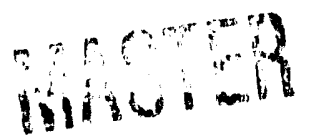




\section{ABSTRACT}

This reports an investigation into the performance of selected scintillation oils and fiber materials to test their applicability in high energy, liquid scintillator calorimetry. Two scintillating oils, Bicron BC-517 and an oil mixed for the MACRO experiment, and two fiber materials, Tefion and GlassClad PS-252, were tested for the following properties: light yield, attenuation length and internal reflection angle. The results of these tests indicated that the scintillation oils and the fiber materials had an overall good performance with lower energies and would meet the requirements of liquid scintillator detection at SSC energies. 


\section{TABLE OF CONTENTS}

\section{Page}

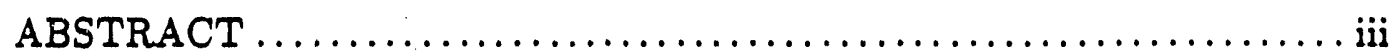

TABLE OF CONTENTS $\ldots \ldots \ldots \ldots \ldots \ldots \ldots \ldots \ldots \ldots \ldots$ iv

LIST OF TABLES $\ldots \ldots \ldots \ldots \ldots \ldots \ldots \ldots \ldots \ldots \ldots \ldots \ldots \ldots \ldots \ldots \ldots$

LIST OF FIGURES $\ldots \ldots \ldots \ldots \ldots \ldots \ldots \ldots \ldots \ldots \ldots \ldots \ldots \ldots \ldots \ldots$

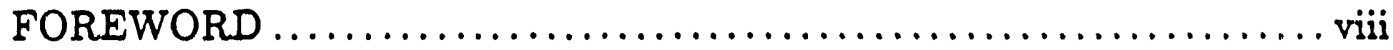

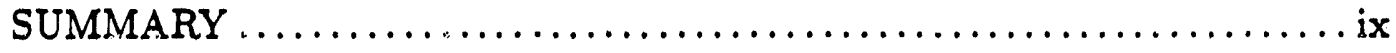

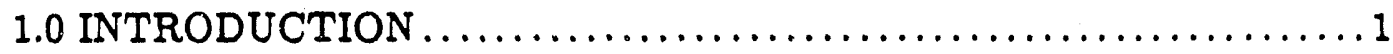

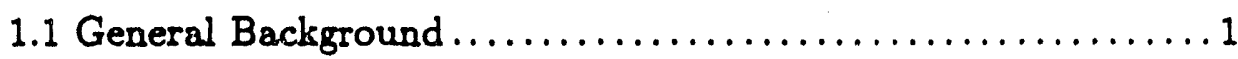

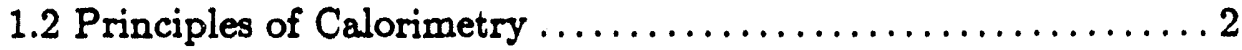

1.2.1 Energy Resolution $\ldots \ldots \ldots \ldots \ldots \ldots \ldots \ldots \ldots \ldots \ldots$

1.2.2 Light Collection........................

1.2.3 Radiation Hardness ....................... 8

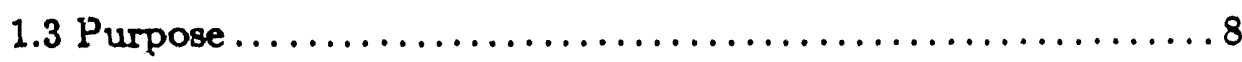

1.4 Research $\operatorname{Plan} \ldots \ldots \ldots \ldots \ldots \ldots \ldots \ldots \ldots \ldots \ldots \ldots \ldots$ 
TABLE OF CONTENTS (Continued)

2.0 DESIGN OF A LIQUID SCINTILLATOR DETECTOR .......... 10

2.1 Detector Properties and Construction................ 10

2.2 Electronics .................................... 12

2.2.1 Discriminator.......................... 13

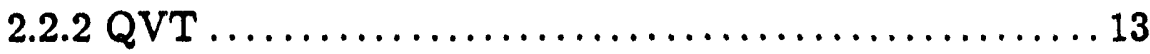

2.2.3 Logic Unit.............................. 14

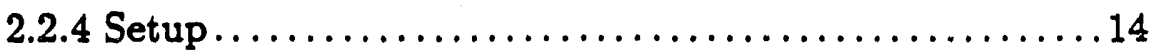

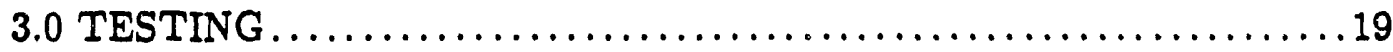

3.1 Refractive Index............................. 19

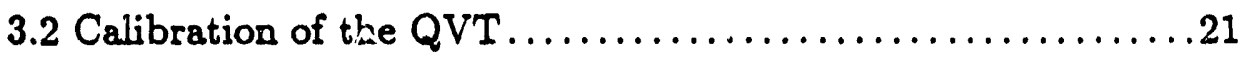

3.3 Light Output................................22

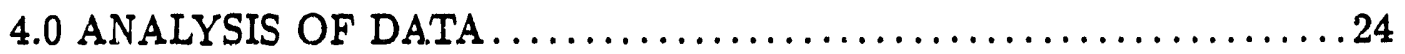

4.1 Systematic Errors in Data............................ 24

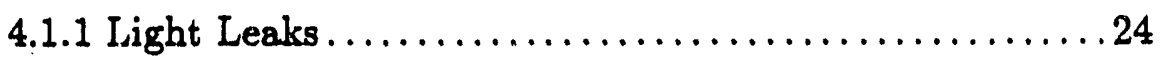

4.1.2 Oil Leaks in the Detector .................... 24

4.1.3 Contaminated Oil........................24

4.1.4 Faulty High Voltage Supply ................. 25

4.1.5 Glass( Ylad-Bicron System ................... 25

4.2 A.nalysis of Pulse height Distribution.................25

4.3 Attenuation Length of Each System ................. 31

4.4 Total Light Output for Each Systern ................. 35 
TABLE OF CONTENTS (Continued)

5.0 COMPUTER SIMULATION PROGRAM $\ldots \ldots \ldots \ldots \ldots \ldots \ldots \ldots \ldots$

5.1 General Features . . . . . . . . . . . . . . . . . . . . . . . . 37

5.1.1 Initial Parameters.............................37

5.1 .2 Variable Parameters ........................... 37

5.1.3 Predicted Parameters .......................... 37

5.1.4 Random Variables .......................... 38

5.1 .5 Ray Tracing $\ldots \ldots \ldots \ldots \ldots \ldots \ldots \ldots \ldots \ldots \ldots \ldots, \ldots \ldots \ldots$

5.1 .6 Simulation Outputs......................... 38

5.2 Results of Simulation............................. 39

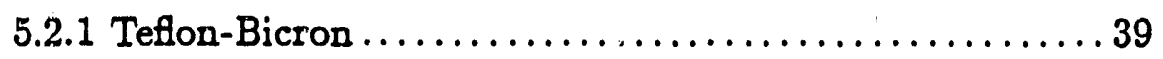

5.2 .1 GlassClad-MACRO ........................ 39

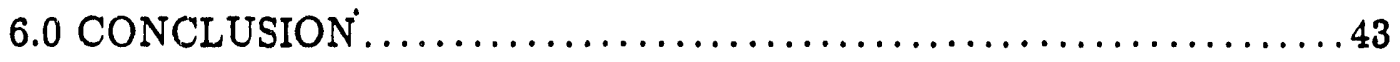

6.1 Results of Measurement and Simulation..............43

6.2 Suitability for Use in Calorimeter Construction .......... 43

6.3 Further Items to Study ........................... 44

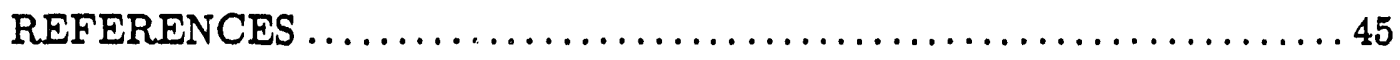

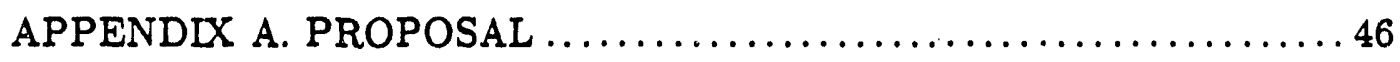

APPENDIX B. PROGRESS REPORT $\ldots \ldots \ldots \ldots \ldots \ldots \ldots \ldots \ldots \ldots, 54$

APPENDIX C. COMPUTER PROGRAM: AVG.FOR..............59

APPENDIX D. COMPUTER PROGRAM: SIMULATION.FOR .......60 


\section{LIST OF TABLES}

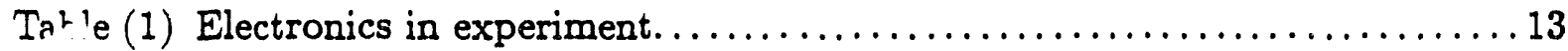

Table (2) Light output of Teflon-Bicron system. ....................... 30

Table (3) Light output of GlassClad-MACRO system. ................... 31

Table (4) Attenuation length of each oil level............................ 34

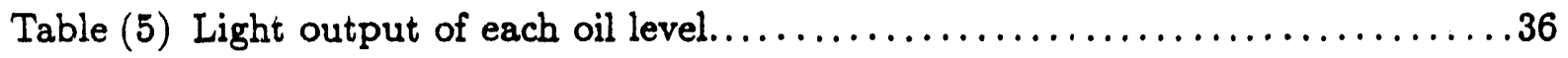




\section{LIST OF FIGURES}

Figure (1) Possible hadronic calorimeter with absorber, fiber scintillator,

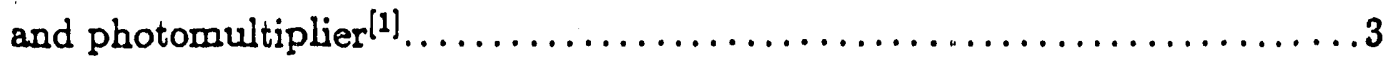

Figure (2) Conceptual design of a single "spaghetti" calorimeter module ${ }^{[1]} \ldots \ldots \ldots \ldots$

Figure (3) Diagram of total internal reflection showing the reflection angle, TIR. . . 6

Figure (4) Sketch of liquid scintillator detector used in experiments........... 11

Figure (5) Sketch showing a muon interacting with the test detector.............16

Figure (6) Electrical layout of the detector system. .................... 18

Figure (7) Sketch of experiment to find reflection angle. ................. 20

Figure (8) Histograms showing variance in light output with distance from PMT. .. 26

Figure (9) Histogram showing variance in light output with oil level............27

Figure (10) Histogram showing variance in light output with oil-material system.....29

Figure (11) Graph of the light output for the Tellon-Bicron system. ............33,41

Figure (12) Graph of the simulated light output for the Teflon-Bicron system.......41

Figure (13) Graph of the light output for the GlassClad-MACRO system. .......33,42

Figure (14) Graph of the simulated light output for the GlassClad-Bicron system.... 42 


\section{FOREWORD}

This report analyzes the data that $w:$ obtained from my University Honors Fellows Research Project. This research tested some properties of two liquid scintillation oils, Bicron BC-517 $\mathrm{L}^{[6]}$ and MACRO ${ }^{[7]}$, and two fiber materials, Teflon ${ }^{[8]}$ and GlassClad PS-252 ${ }^{[9]}$, for their suitability in a fiber, liquid scintillator calorimeter.

The Superconducting Super Collider (SSC) will require new detecting devices in order to obtain information from the high energy particles produced at the SSC energies. Currently, no detector is capable of running at the SSC energies. Before we can build a detector, we must test various components of the detector to see if these components are compatible with SSC energies. For the liquid scintillating fiber calorimeter, we need to test the liquid scintillating oil and the fiber materials. The properties that we centered this report around are: TIR angle of the fiber material, light output of the system and the attenuation lengths of each system. From the data we obtained at the lower energies in cosmic rays, we can extrapolate the energy resolution and the light output at higher energies. 


\section{SUMMARY}

\section{$\underline{\text { Subject }}$}

This report tests various properties of selected fiber materials and scintillation oils for their use in a liquid scintillating fiber calorimeter at the Superconducting Super Collider (SSC). The particular properties of interest are: 1) internal reflection angle (TIR), 2) light yield and 3) attenuation length. From these properties we can calculate the energy resolution of a calorimeter at $4 \mathrm{GeV}$ and the light output anticipated at this energy with the components tested.

\section{Method of Investigation}

This report examines the testing of two scintillating oils, Bicron BC-517 ${ }^{[6]}$ and a scintillation oil mixed for the MACRO experiment at the Gran Sasso Laboratory ${ }^{[7]}$, and of two different fiber materials, Teflon ${ }^{[8]}$ and GlassClad PS$252^{[9]}$. From this examination of these components we can determine if these components are suitable for use in a liquid scintillating fiber calorimeter.

First, this report describes our test cell, a liquid scintillator detector. This description will include the properties and construction of the detector, the electronic set-up, and the $\mu$-telescope (muon-telescope).

Second, this report details the testing of the scintillation oil and fiber materials. The specific properties we are interested in testing is the index of refraction and the number of photoelectrons versus distance from the PMT. The test of the refractive index of the two fiber materials was done directly using a laser, a 1 in rectangular box, paraffin oil of index $1.482^{[10]}$ and aluminum slides coated with the fiber material. The testing procedure for the photoelectrons and attenuation length is a bit more complicated. This required scanning our test detector with 
a $\mu$-telescope at varying distances from the PMT and for different oil heights. We made three different tests using the following combinations: 1) Bicron oil and Teflon, 2) Bicron oil and GlassClad and 3) MACRO oil and GlassClad.

Thirc, this report analyzes our data. From this analysis we will obtain the absorption constant specific to each oil, the total light output of each system and the refleciion constant of each oil. This report also shows how light output varies as a function of: 1) distance from PMT, 2) height of oil and 3) combination of scintillator oil and fiber material.

Fourth, this report explains the basic operation of a computer simulation program that we wrote to aid in the analysis of data. The computer simulation program is ray tracer designed to propagate light through a detector of similar design as the test detector. This report will discuss briefly the general features of the simulation, the free parameters and how well the simulation compares to the data. This report will then discuss possible problems with the simulation program.

\section{Conclusions}

For the Teflon-Bicron system, the attenuation length measured for the oil levels of $4 \mathrm{~mm}$ and $3 \mathrm{~mm}$ is between $0.645 \pm 0.094-0.530 \pm v .071$ meters, and the light output at $0 \mathrm{~cm}$ from the PMT is $\sim 8.01 \pm 1.10$ photoelectrons per $\mathrm{mm}$ of oil. The attenuation lengths increased and the light output per mm of oil decreased for the $2 \mathrm{~mm}$ and $1 \mathrm{~mm}$ oil levels. This could be attributed to the fact that the light output at these levels are arcund one photoelectron. According to the simulation program, the Bicron BC-517 oil has an absorption length of $1.0 \mathrm{~m}$ and the Teflon surface reflects $97.0 \%$ of the light at angles less than the TIR angle of $26^{\circ}$.

For the GlassClad-RiACRO system, the attenuation length measured was $1.488 \pm 0.667$ meters for the $4 \mathrm{~mm}$ oil level and $2.242 \pm 1.435$ meters for the $3 \mathrm{~mm}$ 
oil level. The light output at $0 \mathrm{~cm}$ measured for these cil levels was $0.980 \pm 0.439$ $\mathrm{Pe} / \mathrm{mm}$ of oil for the $4 \mathrm{~mm}$ oil level and $0.647 \pm 0.414 \mathrm{Pe} / \mathrm{mm}$ of oil. These results could be inaccurate because both of the oil levels have light output on the one photoelectron level. Because of this, we took an extra data run at the $6 \mathrm{~mm}$ oil level. The results of this run show the attenuation length was $\sim 61.73 \mathrm{~m}$ and the light output at $0 \mathrm{~cm}$ was $\sim 3.15$ photoelectrons. The simulation program indicates that the reflection constant of the GlassClad is $98.0 \%$. The absorption length of the MACRO oil is known to be 10.0 meters. The TIR of the GlassClad is $17^{\circ}$ and the refractive index is 1.415 .

\section{Recommendations}

The minimum attenuation length necessary for a calorimeter is about $2 \mathrm{~m}$. Both systems, the Teflon-Bicron and the GlassClad-MACRO, have at tenuation lengths which are close enough to warrant further investigation.

The number of photoelectrons necessary for a reasonable electromagnetic resolution at $4 \mathrm{GeV}$ was previously calculated to be 177 photoelectrons. The energy loss of a muon traveling through scintillator was calculate 1 to be $0.2012 \frac{\mathrm{MeV}}{\mathrm{mm} \text { of oil }}$. Converting the number of photoelectrons at $4 \mathrm{GeV}$ to the number of photoelectrons liberated when a muon passes through a mm of oil, we obtain 0.009 photoelectrons per mm of oil. Both detectors produced many more photoelectrons than this, indicating that both materials could possibly be suited for use in a calorimeter.

\section{Further Items to Study}

It will be necessary to obtain clearer data from both GlassClad systems. The data from the GlassClad-Bicron system was inconsistent. The light output for this system should be remeasured to see if there was a systematic error in this 
data that caused the inconsistent data. Also, one should run some tests on a Teflon-MACRO system to see how the light output compares with the other three systems.

Tie next step is to test, these components for their sensitivity to radiation. It is necessary to see if any visible damages occur. After this initial inspection, one needs to set if the attenuation longth, light outfut, reflection constant or the absorption length varies with high radiation dosages. 


\subsection{INTRODUCTION}

\subsection{General Background}

With the Superconducting Super Collider (SSC) less than a decade away, scientists and engineers are already striving to adrance in technology in the fields of superconductivity, computers, data acquisition and detector development to support experiments being planned for this facility. R\&D for detection devices is onc of the fields of research being studied at Teras A\&M. Currently, most high energy accelerators use magnetic spectrometry to detect high energy particles. Recent research in calor:metric techniques suggest that a calorimeter (total energy absorbin $\vec{b}$ detector) could out perform magnetic spectrometry at the higher an- $^{-}$ ergies expected at the SSC. While many of the calorimetric techniques work well at the energies currently available, more R\&D is needed for SSC energies. High energy physicists at Texas A\&M are now researching liquid scintillators to design a scirtillating fiber calorimeter ${ }^{[1]}$.

Fiber calorimetry is a relatively new area of research in cietection instruments. The calorimeter is made by taking very thin scintillating fibers and embedding them in lead in a hexagonal geometry. Originally, the fiber calorimeter was designed for use with plastic scintillators; however, these plastic fibers are very sensitive to damage by high doses of radiation. To overcome this disadvantage, we are proposing to replace the solid plastic scintillating fibers with hollow tubes filled with liquid scintillating material, which is known to be much more radiation resistant than solid plastic scintillator. The geometry of the fiber calorimeter does appear to be superior to most other designs. When incorporated with the ideal scintillator, the fiber calorimeter could become the detector of the future ${ }^{[1]}$. 


\subsection{Principles of Calorimetry}

A calorimeter is a devise used to measure the total energy of an incident, high-energy particle as shown in Firure 1. The way that a calorimeter detects and measures a particle's energy is a two step process: absorption and detection. The incident particle interacts with a large detector mass. This mass absorbs the initial particle and, in turn, generates secondary particles; these particles then interact with the detector mass $t$. produce tertiary partiules; and this process continues until all of the incident energy is in the form of many elementary particles ${ }^{[2]}$. These elementary particles are than detected by the medium of the calorimeter (such as scintillator).

One type of calorimeter that Texas $A \& M$ is interested in researching is a liquid scintillator fiber calorimeter or "spaghetti" calorimeter as shown in Figure 2. The detection medium of the "spaghetti" calorimeter is a group of scintillating fibers a: ranged in a hexagonal shape. A scintillating fiber is a long hollow tube of $\sim 1 \mathrm{~mm}$ diameter. The fiber is coated on the inside with a material known to give a high internal reflection angle.

When a light wave traveling in an optically dense medium (large refractive index) comes in contact with another medium of a lower refractive index, some of the total light is reflected back into the dense medium and some of the light is transmitted into the less dense medium. In the case of the fiber scintillator, the dense medium is the liquid scintillator, and the fiber material is the less dense medium. The angle between the light ray and the boundary of the two mediums is denoted as $\theta$. At the critical angle, $\theta_{c}$, all of the light will be reflected and none transmitted. So, for all light that falls upon this boundary at an angle less than the critical angle $\theta_{c}$, the light wiii be completely reflected as shown in Figure 3. 
FIGURE 1

Hadronic Calorimeter

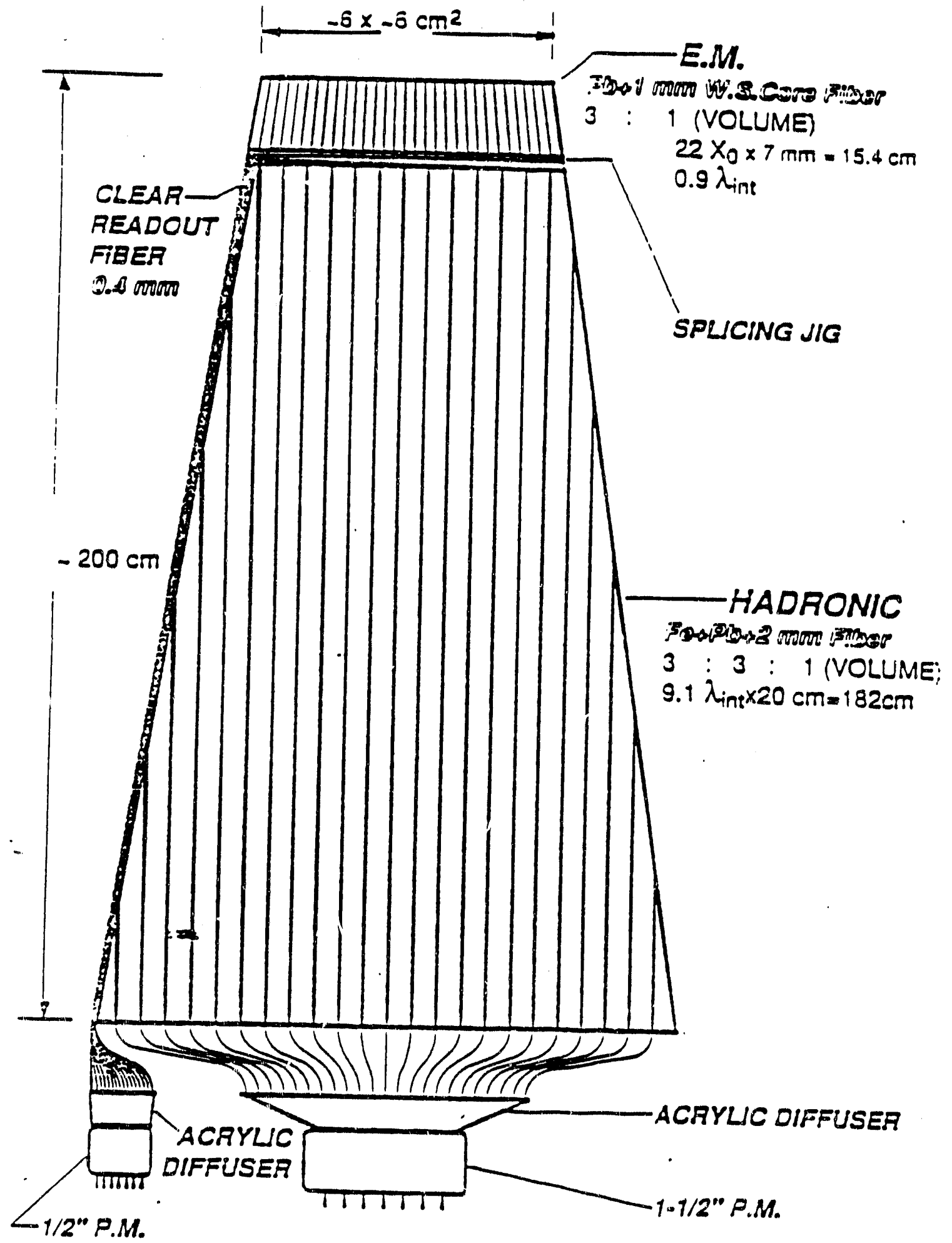




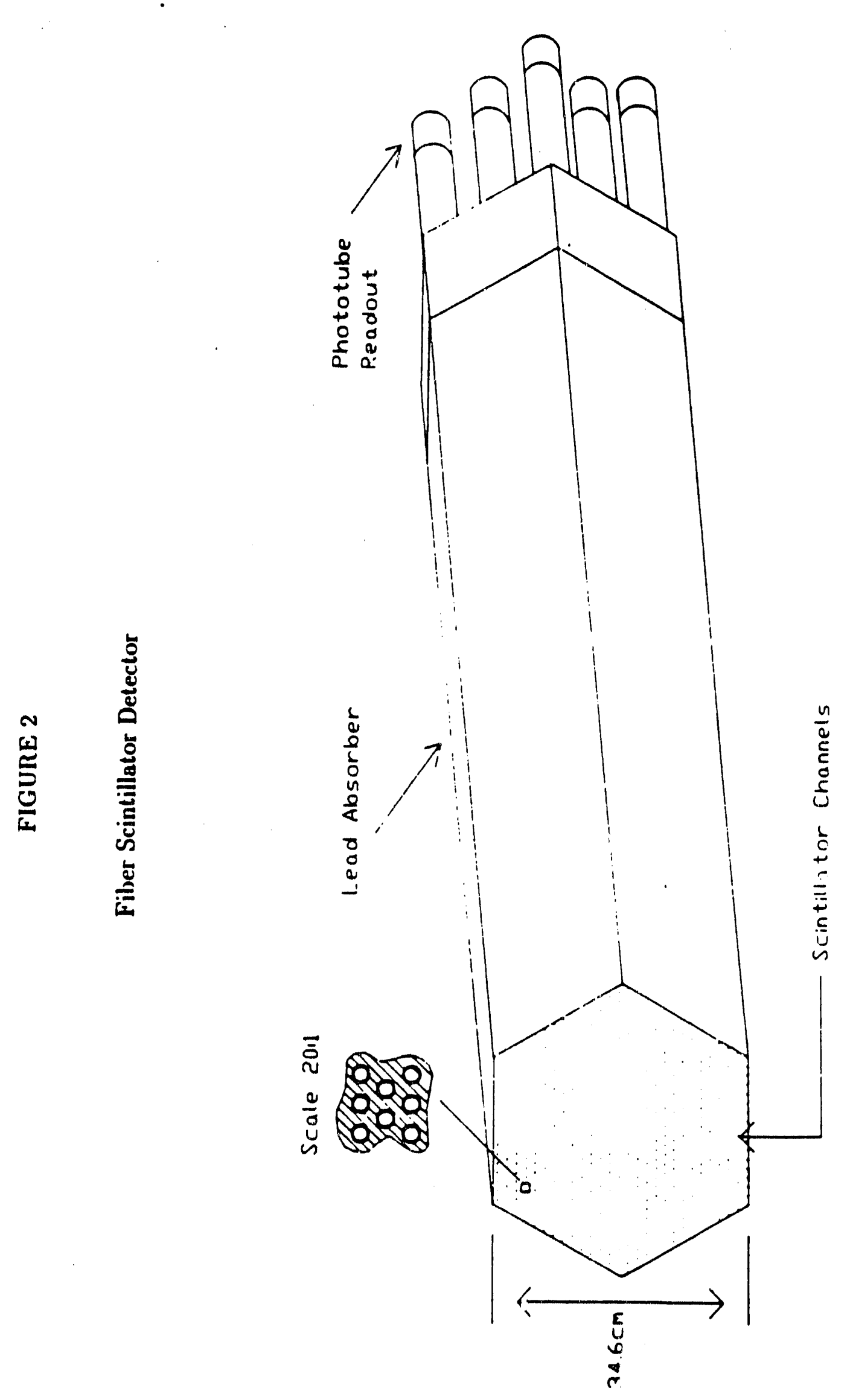


This phenomena is called total internal reflection. This angle can be calculated using Snell's Law and the indicies of refraction:

$$
\sin \left(\frac{\pi}{2}-\theta_{c}\right)=\frac{n_{1}}{N_{2}} \quad\left(n_{1}<N_{2}\right)
$$

where $n_{1}$ is the refractive index of the scintillation oil, $N_{2}$ is the refractive index of the fiber material, and $\theta_{c}$ is the angle between the two mediums measured in radians. As the difference between $n_{1}$ and $N_{2}$ increases, the internal reflection angle increases. This is very important to us, because the amount of light output for a detector is directly proportional to the reflection angle.

The coated fiber is then filled with a liquid scintillator. When an innizing particle interacts with the liquid scintillator, the scintillator emits light proportional to the energy lost in transit. The photons are then propagated down the inside of the fiber to a photomultiplier tube, PMT, detects the number of transmitted photons.

The primary research necessary is finding the ideal materials to construct this calorimeter. The main components of the detector itself are the scintillating oil, the fiber material, the photomultiplier tubes and the converter. In particular, a detector must have a good energy resolution (which is related to the light output), good light collection, high radiation resistivity and a reasonable cost ${ }^{[3]}$.

1.2.1 Energy Resolution For a typical large scale calorimeter, the energy resolution $\left(\frac{\sigma}{E}\right)$ necessary for an electromagnetic response is $\frac{0.15}{\sqrt{E}}$ or better ${ }^{[3]}$. At energies on the order of $4 \mathrm{GeV}$ (SSC energies), the energy resolution is about $7.5 \%$. Since $\sigma$ equals the square root of the number of particles sampled ${ }^{[4]}$, and the energy, $E$, equals the number of particles, the energy resolution equals the inverse of the square root of the number of particles sampled: 


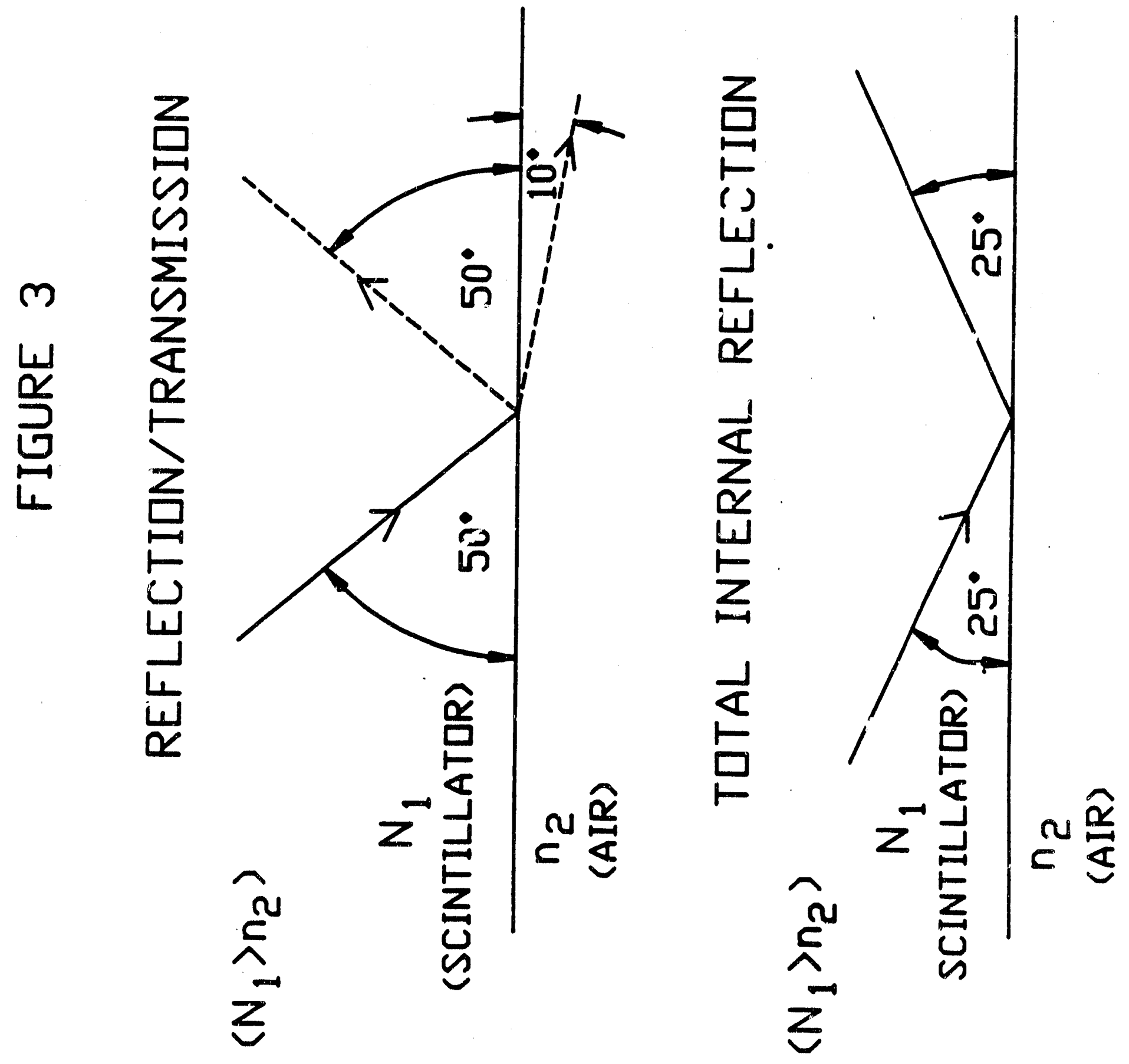




$$
\frac{\sigma}{E}=\frac{0.15}{\sqrt{E}}=\frac{1}{\sqrt{N_{P_{e}}}}
$$

For $4 \mathrm{GeV}$ of energy, an electromagnetic detector with an energy resolution of $\frac{0.13}{\sqrt{E}}$ or better would have a light output of 177 photoelectrons. A calorimeter detecting energies at the $4 \mathrm{GeV}$ level needs the light output to be on the order of 177 photoelectrons.

1.2.2 Light Collection In a scintillator detector light loss can occur in two different ways: 1) through transmission or absorption at the boundary and 2) through absorption by the scintillator. Since the total light output is inversely proportional to the square of the resolution, a scintillating detector must have a high light output.

The absorption at the boundary is determined by the quotient of the refractive indicies of the scintillator and the fiber material. For large differences in indicies, the reflection angle (TIR) between the two mediums increases. This will in turn allow more light to be collected by the scintillator calorimeter. For high light output, it is necessary therefore, to bave a high TIR between the scintillator and the fiber material.

For large detectors, like those employed at particle accelerators, the absorption of light by the scintillator is important, because the path length of the light is on the order of a few meters. The attenuation length is defined as the length after which the light intensity is reduced by a factor of $e^{[4 .]}$ :

$$
E=E_{0} e^{\frac{-a}{\lambda}}
$$

where $E$ is the energy, $E_{0}$ is the initial energy, $x$ is the path length and $\lambda_{A}$ is 
the attenuation length. For accelerator detectors, the attenuation length must be $\sim 2 \mathrm{~m}$.

1.2.3 Radiation Hardness "Since the SSC is extremely radioactive, the calorimeter must be resistive to high dosages of radiation $\left(\geq 10^{6} \mathrm{rad} / \text { year }\right)^{[5]}$. Many raaterials are known to break down after dosages on this order of magnitude, so the components of the calorimeter must be hardened against radiation.

\subsection{Purpose}

The purpose of this paper is to report on tests of properties of selected fiber materials and scintillation oils for their use in a liquid scintillating fiber calorimeter at the Superconducting Super Collider (SSC). The particular properties of interest are: 1) internal reflection angle (TIR), 2) light yield and 3) attenuation length. From these properties we can calculate the energy resolution of a calorimeter at 4 $\mathrm{GeV}$ with the components tested.

\subsection{Research Plan}

In this report we will examine the testing of two scintillating oils, Bicron $\mathrm{BC}-517^{[6]}$ and a scintillation oil mixed for the MACRO experiment at the Gran Sasso Laboratory ${ }^{[7]}$, and of two different fiber materials, Teflon ${ }^{[8]}$ and GlassClad PS-252 ${ }^{[9]}$.

First, we will describe our test cell, a liquid scintillator detector. This description will include the properties and construction of the detector, the electronic set-up, and the $\mu$-telescope (muon-telescope).

Second, we will detail the testing of the scintillation oil and fiber materials. The specific properties we are interested in testing is the index of refraction and 
the number of phntoelectrons versus distance from the PMT. The test of the refractive index of the two fiber materials was done directly using a laser, a clear rectangular box, paraffin oil of index $1.482^{[10]}$ and aluminum slides coated with the fiber material. The testirig procedure for the photoelectrons and attenuation length is a bit more complicated. This required scanning our test detector with a $\mu$-telescope at varying distances from the PMT and for different oil heights. We made bree different tests using the following combinations: 1) Bicron oil and Teflon, 2) Bicron oil and GlassClad and 3) MACRO oil and GlassClad.

Third, we will analyze our data. From this analysis we will obtain the absorption constant specific to each oil, the total light output of each system and the reflection constant of each oil. We will also show how light output varies as a function of: 1) distance from PMT, 2) height of oil and 3) combination of scintillator oil and fiber material.

Fourth, we will explain the basic operation of a computer simulation program that we wrote to aid in the analysis of data. The computer simulation program is ray tracer designed to propagate light through a detector of similar design as the test detector. We will discuss briefly the general features of the simulation, the free parameters and how well the simulation compares to the data. We will then discuss possible problems with the simulation program. 


\subsection{DESIGN OF LIQUID SCINTILLATOR DETTCTOR}

\subsection{Detector Properties and Construction}

The outer shell of the detector consisted of a rectangular slab of PVC (48" $\times$ $\left.4.5^{\prime \prime} \times 1.0^{\prime \prime}\right)$ with a center core $\left(46^{\prime \prime} \times 2.0^{\prime \prime} \times 1.0^{\prime \prime}\right)$ removed from it as shown in Figure 4. Then a rectangular window was cut at both ends of the detector, and affixed to each end is a clear plastic window. Connected to both the top and the Lottom of the detector were two aluminum plates $\left(48^{\prime \prime} \times 4.5^{\prime \prime} \times .025^{\prime \prime}\right)$. Two $3 / 8$ inch diameter holes, one 1/4 inch higher than the other, were cut on each side of: the detector for filling and removing scintillation oil. To collect all available light, the entire inside of the detector was coated with an adhesive Teflon.

We coated aluminum strips $\left(48^{\prime \prime} \times 2^{\prime \prime}\right)$ with both Teflon and GlassClad. It was necessary to raise each strip to the height of the bottom of the window. To do this, we create eight small platforms of equal heights and glued them at even spacings on the bottom of the detector.

Plastic tubes were connected to the two holes cut into the detector. The lower of these tubes was used to fill the detector with scintillation oil, the other was used to allow air to escape from the detector. The height of the oil is measured from the test strip to the air oil interface. We monitored the height by viewing the oil level through one of the windows and measuring the height with a height gauge.

After the height of the oil was set, we placed a photomultiplier tube (PMT) onto the window with the test strip flush against it. After the PMT was in place, we taped all areas of the detector that could be exposed to light (light leak testing) with black electrical tape. This is to insure that all of the light detected by the PMT is light emitted from the scintillator and not from any external light source. After the detector was completely light leak tested, it was ready for cosmic ray 
FIGURE 4

SKETCH OF LIQUID SCINTILLATOR DETECTOR

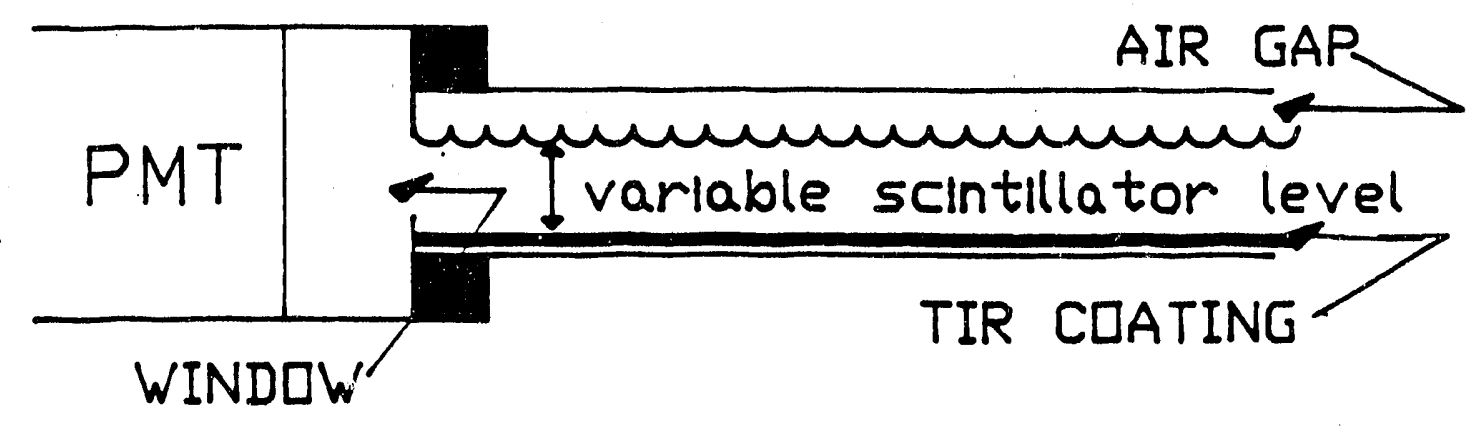


testing.

A photomultiplier tube, or PMT, is an sustrument that collects light and converts light to an electric current through the photoelectric effect. It consists of a photocathode coated with alkali metals, where electrons are liberated by the photoelectric effect. When a photon strikes the window surface, the electrons emitted travel through a chain of secondary-emission electrodes (dynodes) at successively larger potentials. The dynodes amplify the signal by a factor of about $10^{7[2]}$. A PMT records all of the light output from the scintillating material by converting the light into electrons via the photoelectric effect. The resulting signal is amplified by a factor of $10^{7}$ so that the signal is large enough to be recorded.

The term photoelectron is the unit used to refer to the light output of a system. When a photon hits the surface of the PMT it liberates an electron through the photoelectric effect. The total number of electrons produced is directly proportional to the number of photons striking the surface of the PMT.

\subsection{Electronics}

The photoelectrons, after passing through a series of dynodes, form a current. This current can be analyzed with various electronics. Before we discuss the actual electronic setup, we would like to list the components used and briefly explain some of the components functions. 
TABLE 1

\section{ELECTRONICS IN EXPERIMENT}

\begin{tabular}{|l|l|l|}
\hline Component & Model Number & Manufacturer \\
\hline System Bin & $401 \mathrm{~A}$ & ORTEC \\
\hline High Voltage Supply & 556 & ORTEC \\
\hline Power Supply & $415 \mathrm{~B}$ & Fluke \\
\hline QVT Multichannel Analyzer & 3001 & LeCROY \\
\hline Printer Interf ce & 3157 & LeCROY \\
\hline Digital Printer & DPP-Q7 & DATEL \\
\hline 4-Fold Logic Unit & $365 \mathrm{AL}$ & LeCROY \\
\hline Quad Discriminator & 821 & LeCROY \\
\hline Photomultiplier Amplinier & $612 \mathrm{AM}$ & LeCROY \\
\hline Oscilloscope & 485 & Tektronix \\
\hline BCD Scaler & $1880 \mathrm{~B}$ & Jorway \\
\hline Voltage Distribution Unit & & Harvard \\
\hline
\end{tabular}

2.2.1 Discriminator A discriminator is a device that responds only to input signals above a certain threshold value. Low voltages coming from the PMT (i.e. background noise) will not register in the discriminator. If a signal above the threshold value enters the discriminator, a logic signal is issued from the discriminator. Discriminators are typically used for triggering (sending a signal to other electronic devices when an event occurs). In our experiment the threshold vilue was set at $30 \mathrm{mV}$ and the discriminator vas used to trigger the QVT.

2.2.2 QVT A QVT multichannel analyzer works by integrating the input charge 
over the gate time. This charge is equal to the n"umber of photons to the total charge of the electrons liberated at the surface of the PMT when photons strike the surface. The amount of riarge of the signal is digitized. The QVT then takes this digitized number and increments a memory channel whose address is proportional to the digitalized value $e^{[4]}$. All incoming pulses are sorted out by their integrated charge and are stored in a channel respective of the charge of the incoming pulse. The QVT used for our experiment has 256 channels each corresponding to 1 picoCoulomb of charge. From the spectrum of charge produced by the incoming spectrum, we can calculate the average charge produced by an event, and thus the average light output of an event.

2.2.3 Logic Unit The logic unit compares two or more signals to see if they are coincident in time. In our case if, and only if, all signals inputted are coincident in time, will the logic unit output a signal.

2.2.4 Setup All of our experiments are conducted with the high voltage supply set at 2,100 Volts. The voltage supply is then connected to the voltage distribution unit used to power each of the 4 PMTs. One PMT was connected to the detector and the other three were connected to a $\mu$-telescope. We use the voltage distribution unit to lower the out-going voltage to our detector to 1,750 Volts and to 1,625 Volts for our $\mu$-telescope. The reason for the voltage difference is that higher voltages increase the gain of the $\mu$-telescope. Our $\mu$-telescope is composed of three plastic scintillators which have a much higher light output than liquid scintillator. So, we have the telescope at the lowest roltage setting possible with our setup.

The term 'telescope' refers to a system of detectors arranged in such a way as 
to allow only particles traveling through the entire system of detectors to trigger the QVT as seen in Figure 5. Each of the detectors was typically connected to a discriminator to block out low amplitude noise. The signals from the discriminator travel to a coincident logic unit. When all three signals from the discriminators coincide in time, a particle has traveled through the system of detectors. The system of detectors, the discriminators and the logic unit together constitute the telescope. In our case, when the detector detects an event, it sends a signal to the gate of the QVT, thus triggering the QVT. As the telescope is moveable, we are able to pinpoint when and where an event occurs.

A $\mu$-telescope detects when a muon passes through the telescope system. We are testing with cosmic rays which are predominately $\mu$ mesons with an energy in the range of a few $\mathrm{GeV}$. We can easily set up our telescope system to detect these muons, since it is unlikely for lower energy cosmic rãy particles to travel through the telescope. Muons in this energy range produce an energy loss of 1.95 $\frac{M e V}{g / \mathrm{cm}^{2}}[11]$ when passing through the scintillator. This energy loss is often called the "minimum ionizing energy loss" due to the slope of the $\frac{d E}{d x}$ curve as a function of energy in the range of muon energies. For a liquid scintillator with a density of $1.032 \mathrm{~g} / \mathrm{cm}^{3[11]}$, the ionizing energy is $0.2012 \frac{\mathrm{MeV}}{\mathrm{mm} \text { of oil }}$.

The output signal from ur detector went into an attenuator. The attenuator reduced the amplitude of the si jal by a factor of 2 for every $6 \mathrm{~dB}$. It was sometimes necessary to do this because sometimes the total charge delivered can exceed the input scale of the QVT. If this occurs, all signals over the full scale value will be entered into the last channel of the QVT anyway. After attenuation, the signal travels through $128 \mathrm{ft}$ of cable, which delays the signal by 170 n.s. The signal was then passed through a capacitor which offsets the DC signal. This eliminated any 
FIGURE 5

TEST CELL FUR LIQUID/CDATTNG

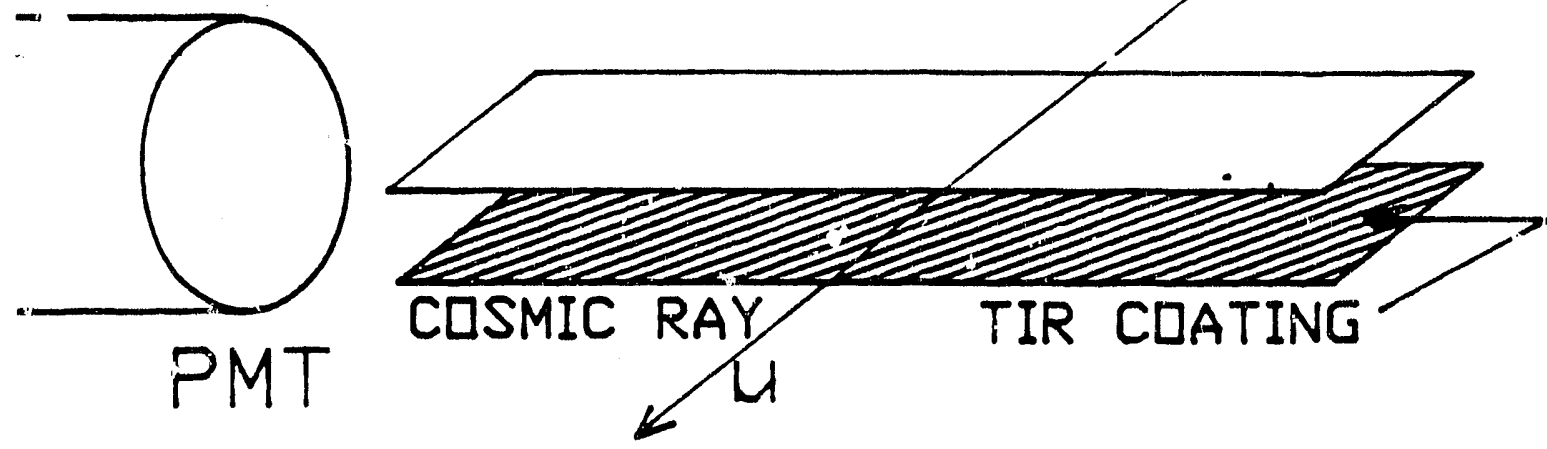


fluctuations in the DC signal which could interfere with the data. The signal finally entered the q-input of the QVT, and, if the gate was "open," the QVT analyzed the signal. The electrical diagram of this is shown in rigure 6 . The way the QVT analyzed events was by first measuring the energy of the signal and secondly, by incrementing the count of the channel corresponding to that energy. After the data run was complete, the number of counts in each channel was be printed out and analyzed. 


\section{FITJURE 6 \\ ELECTRINICS LUGIC}

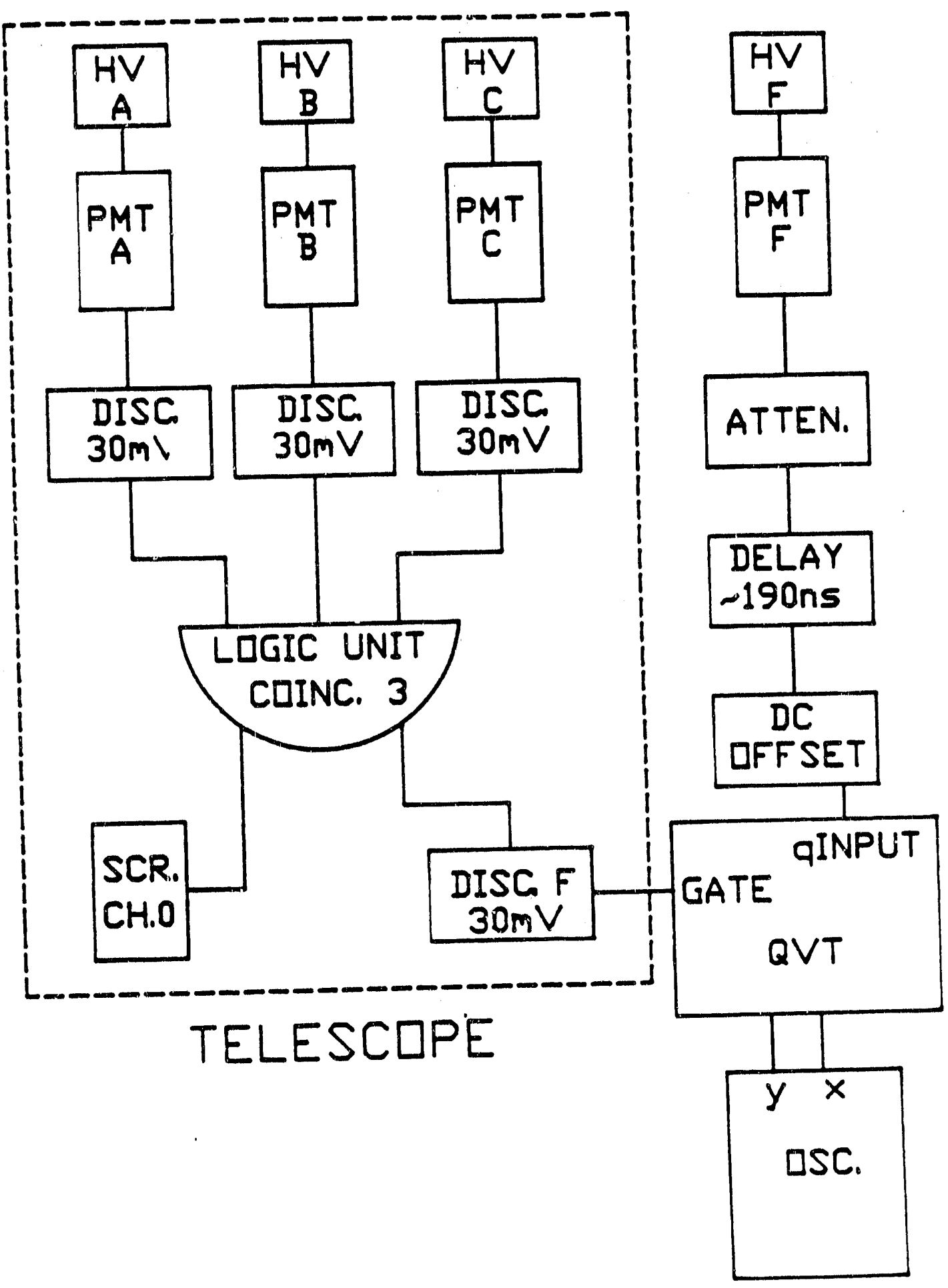




\subsection{TESTING}

\subsection{Refractive Index}

The refractive index of the scintillation oil and of the fiber material is instrumental in calculating the total internal reflection angle (TIR). Since the propagation of the photons along the length of the detector is dependent on the TIR, it is necessary to know the refractive index of the scintillation oil and of the fiber material. In a fiber scintillator the percentage of light that falls within the TIR is

$$
\begin{aligned}
& \text { Percentage }=\frac{1}{4 \pi} \int_{-T I R}^{T I R} d \phi \int_{\frac{\pi}{3}-T I R}^{\frac{\pi}{2}+2 T I R} \sin \theta d \theta, \\
& \text { Percentage }=\left(\frac{T I R}{2 \pi}\right)(\sin (2 T I R)+\sin (T I R)) .
\end{aligned}
$$

The refractive index of each of the scintillation oils was known to be 1.48, the same as the refractive index of paraffin oil. The refractive index of Teflon was also known to be about $1.33^{[12]}$. The unknown index of refraction was that of the GlassClad. To determine the index of refraction for the GlassClad, we had to construct an index of refraction measuring device.

The device consists of a clear plastic holding tank $\left(8^{\prime \prime} \times 4^{\prime \prime} \times 4^{\prime \prime}\right)$ filled with paraffin oil. Aluminum strips coated with various fiber materials are laid on the bottom of the tank. A laser beam is propagated into the oil and onto the test strips. The angle between the test strips and the laser beam is varied until total reflection as shown in Figure 7. This phenomenon is observable because: 1) the beam becomes noticeably brighter in the oil, and 2) there is no observable scattering on the surface of the test strips.

The test was first conducted using a Teflon coated aluminum strip. The test showed that the Teflon strip had a TIR of $26^{\circ} \pm 1^{\circ}$ and an index of refraction of 


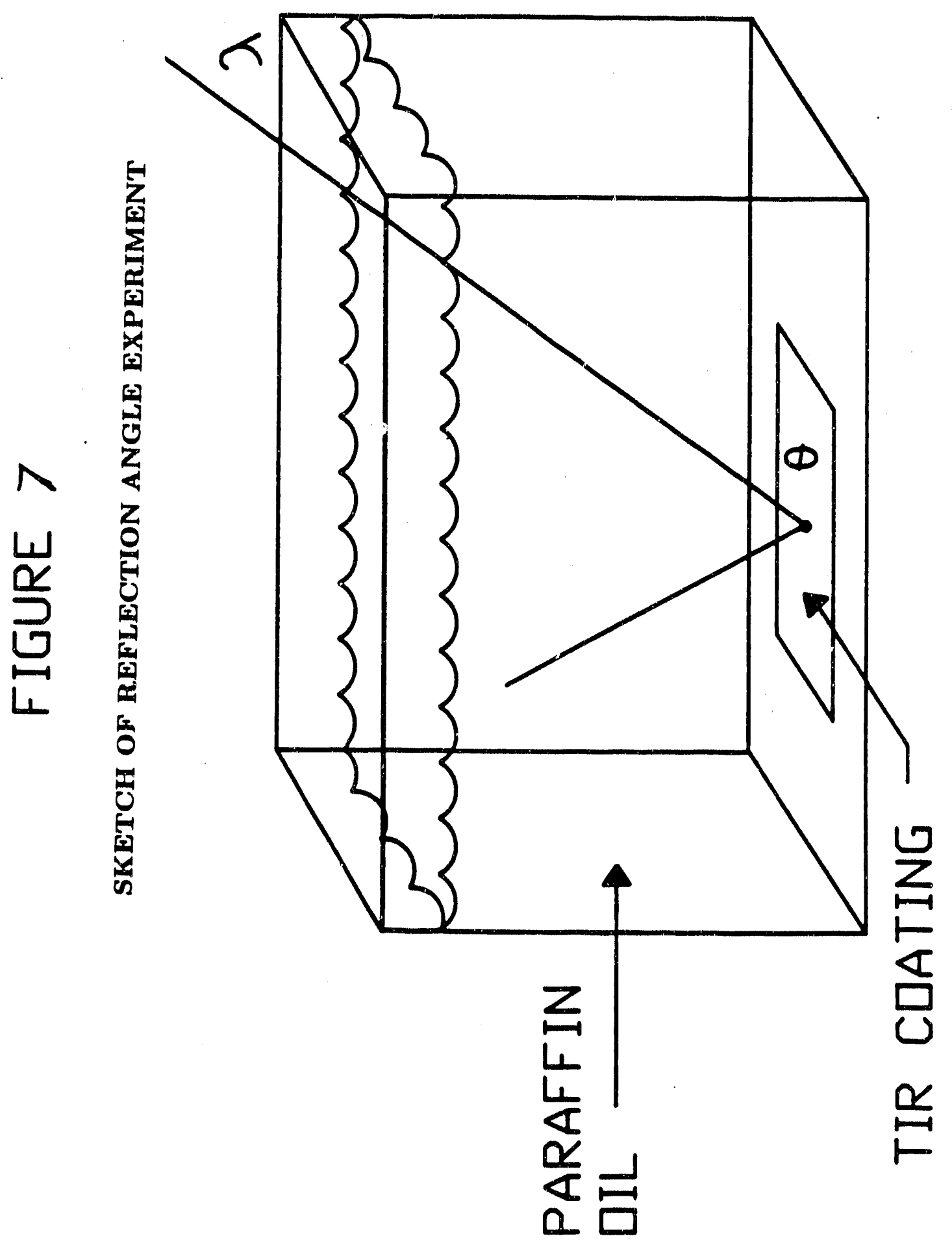


$1.330 \pm 0.011$. This was consistent with the predicted refractive index. The next step was to find the refractive index of the GlassClad. We prepared many strips varying the amounts of coating, the etching of the aluminum strips, the curing process, three different types of GlassClad, the concentration of the GlassClad and the methods of application. The reason for producing so many different strips was that we wanted to find the method of coating the aluminum strips that gave us the smoothest coatings, was the easiest to apply and possibly could produce a method for coating the inside of a $1 \mathrm{~mm}$ fiber scintillator.

All of the coatings had the same refractive index and TIR. The TIR measured was $17^{\circ} \pm 1^{\circ}$ and the index of refraction was thus calculated to be $1.415 \pm 0.008$. This angle was a little lower than desired, but still reasonable for detector studies.

The percentage of light collected by a liquid scintillator using the GlassClad material is $\sim 4.0 \%$. The percentage of light collected by a liquid scintillator using a Teflon coating is $\sim 8.9 \%$.

In our experiment as the boundary between the scintillation oil and the fiber material is not perfect, some of the light will be transmitted into the fiber material. For the purpose of clarity I would like to point out that my definition of the TIR (total internally reflecting angle) is the maximum angle between the incident photon and the boundary between the mediums where the photon is almost totally reflected. The amount of light reflected is not $100 \%$ because the boundary between the two mediums is not perfect. In most texts the reflection angle is drawn between the incident ray and the normal, but this is not the case in my calculations.

\subsection{Calibration of the QVT}

As mentioned earlier, the channel numbers in the QVT correspond to the 
integrated charge of the PMT and this charge corresponds to the number of photoelectrons entering the multiplying procedure of the PMT during an event. The average number of photons that hit the PMT equals a constant multiplicd by the average channel number in the QVT. This number is constant with une PMTdynode combination. To find the number of photons, it is necessary to calculate the value for this constant.

To find this constant, we let the PMT of our detector trigger itself. What this means is that we let the test detector trigger the $\mathrm{QVT}$ when a minimum signal is present at the PMT anode. Then, we calculated the average channel number making any correction for attenuation or amplification. We calculated this constant to be $3.752 \pm 1.138 \frac{p C}{P_{e}}$ at $14 \mathrm{~dB}$. To find the number of photoelectrons, all that we need to do is divide the average channel number measured during a test run by this constant.

\subsection{Light Output}

The procedures described within this section constituted the bulk of our experiment. For our initial setup, we used a Teflon coated strip and $2 \mathrm{~mm}$ of Bicron scintillation oil. We set the $\mu$-telescope at a distance of $10 \mathrm{~cm}$ from the PMT. We began taking data, adjusting the attenuation to get an optimal distribution of channels in the QVT.

These measurements were repeated moving the $\mu$-telescope to successively 35 $\mathrm{cm}, 60 \mathrm{~cm}, 85 \mathrm{~cm}$ and $110 \mathrm{~cm}$ from the PMT. Where data was received with a good channel distribution, we changed the height of oil $(4 \mathrm{~mm}, 3 \mathrm{~mm}, 2 \mathrm{~mm}, 1$ $\mathrm{mm}$ ) and remeasured the average channel distribution for the varying distances from the PMT. When all of these measurements were completed with the Teflon- 
Bicron oil combination, we removed the Teflon strip and placed a strip coated with Glass Clad and refilled the counter with the Bicron oil. We remeasured the average channel number at the five different distances and the four different heights. When we completed these measurements, we replaced the Bicron oil with the MACRO oil. We started to take new measurements with the GlassClad-MACRO system, but we ran out of time. The only measurements that we have obtained are those at the six, four and three millimeter oil heights with the $\mu$-telescope scanned across the length of the detector.

The data runs were lengthy (from eight hours to two days), and initially there were many systematic errors that resulted in bad data. This is why we have a limited amount of data at this time.

To find the average number of photoelectrons for each data run, we wrote a computer program (Avg.for). See Appendix D. This program inputs the entire data for a run. The data is in the form of number of counts at a given channel number for 256 channel numbers. $A v g$ reads in the data and, for a given pedestal value and attenuation setting, outputs the number of photoelectrons produced and the root mean square deviation for this average. So, for each data run, we can calculate the average photoelectron and compare these results. 


\subsection{ANALYSIS OF DATA}

\subsection{Systematic Errors in Data}

4.1.1 Light Leaks This proved to be the most common problem encountered in the data taking. Light leaks occur when external light is detected by the PMT, which results in a higher light output than an actual reading. To prevent light leaks, the anode signal from the PMT is analyzed with an oscilloscope. If there are light leaks, the number of pulses will increase. To repair light leaks we must view the anode signal and tape every part of the detector that could be exposed to external light sources. Once the number of pulses has decreased to a minimum (this is a judgement call based on months of experience), the detector is said to be leak tight.

4.1.2 Oil Leaks in the Detector The hole through which the fill tube was connected started leaking oil. This leak resulted in a lowering of the oil level inside the PMT and after a short time in the break down of the tape used to cover the light leaks, which in turn re-exposed the detector to external light. This oil leak was repaired by removing the tubes, glueing the old holes in the detector and redrilling and tapping new holes for the oil fill tubes. Another oil leak developed at one of the screw holes for the bottom of the detector. A seal was attempted using RTV, but this did not completely solve the problem. 'This hole still leaks, but over the time spans of the data runs, an unappreciable amount.

\subsubsection{Contaminated Oil One set of data (Bicron-Teflon at the $2 \mathrm{~mm}$ oil level)} had an extremely low light output. When we changed the oil, the light output at that level improved greatly. This oil had been removed from the detector, transfered to several containers, and was reused in the detector. Our conclusion 
was that the external handling caused some contamination to the oil.

4.1.4 Faulty High Voltage Supply The Fluke High Voltage Supply began putting out Voltages over 2500 Volts. Upon examining the Voltage Supply, we noticed that the Voltage Supply had a faulty reference resistor. We replaced that Voltage Supply unit with the ORTEC Voltage Supply.

4.1.5 GlassClad-Bicron System As the light output measured in this system was not consistent, no analysis is available for this system. The e act cause of the bad data is unknown.

\subsection{Analysis of Pulse Height Distribution}

As mentioned earlier, the amplitude of a signal from the PMT is digitized and stored in a channel number. This channel number is directly proportional to the number of photons that strike a photon during an event. From the distribution, we can calculate the average number of photoelectrons (Channel number). If we compare these distributions, we can notice three natural tendencies:

1. As the $\mu$-telescope is moved farther away from the PMT, the average channel number decreases as shown in Figure 8. This decrease is caused by two things: A) the mean path length is increasing (which means more light is being absorbed by the scintillator), and B) the number of bounces necessary to reach the PMT of the average photon increases, thus increasing the chance for the light to be absorbed at the coating-oil interface.

2. As the oil level is reduced, the average channel number decreases as shown Figure 9. This is because a muon loses $0.2 \frac{\mathrm{MeV}}{\mathrm{mm} \text { of oil }}$. So the energy loss is proportional to the 
FIGURE 8

VARIATION OF LIGHT OUTPUT WITH DISTANCE FROM PMT

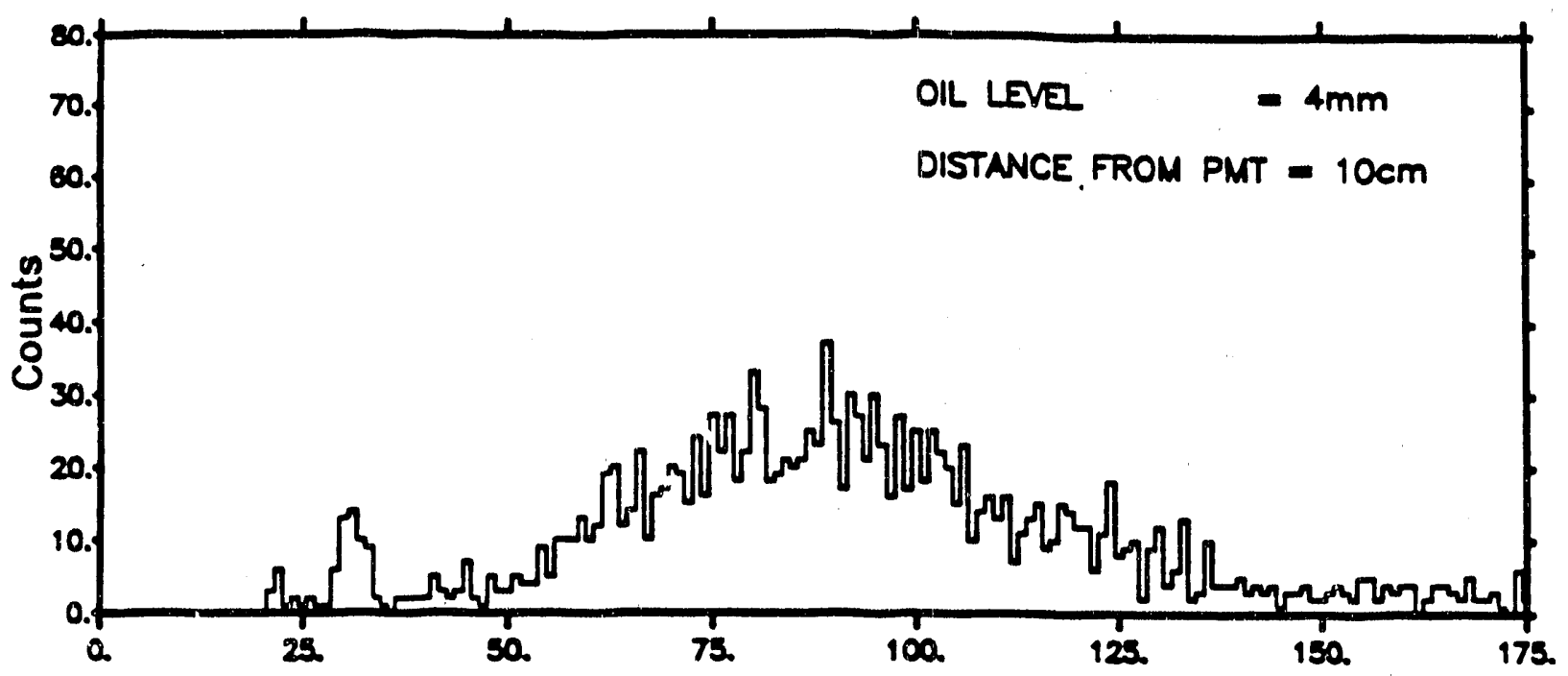

Channel Number

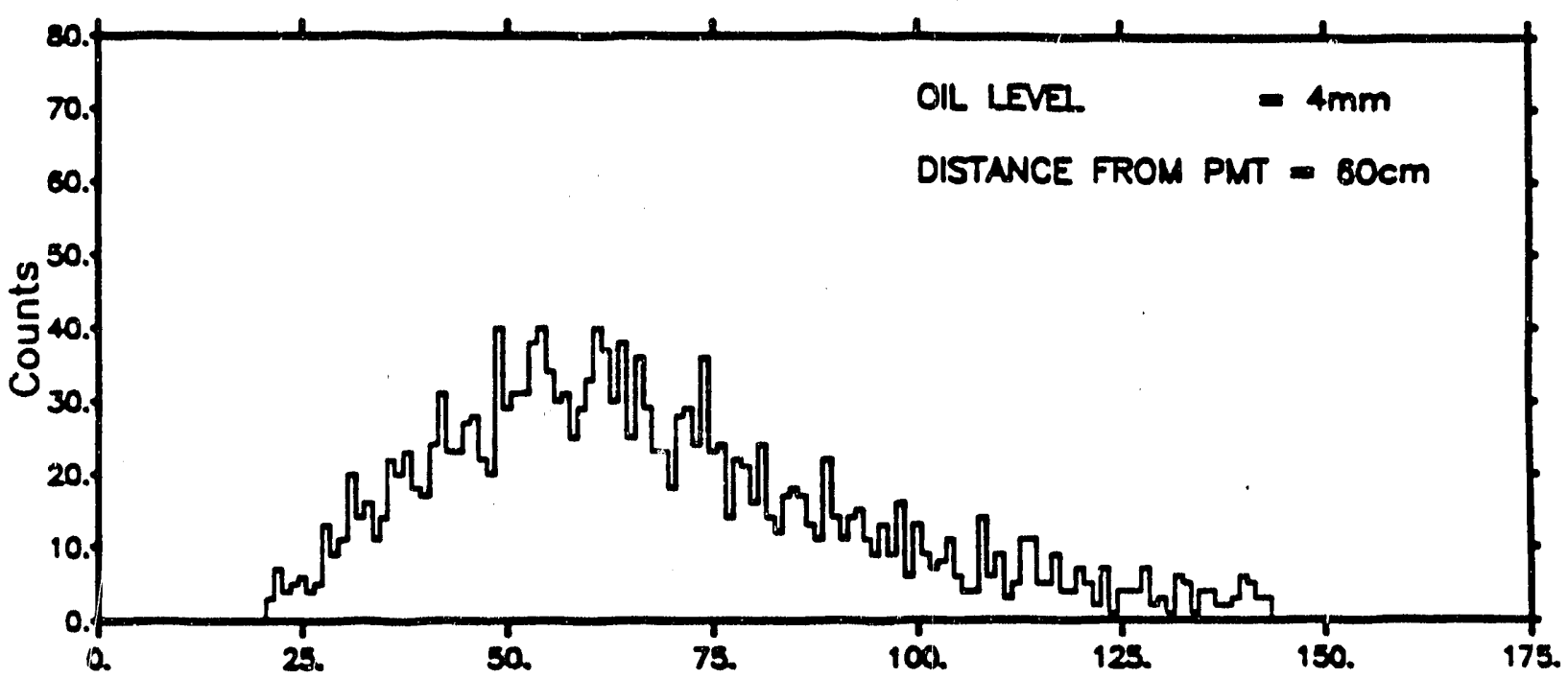

Channel Number

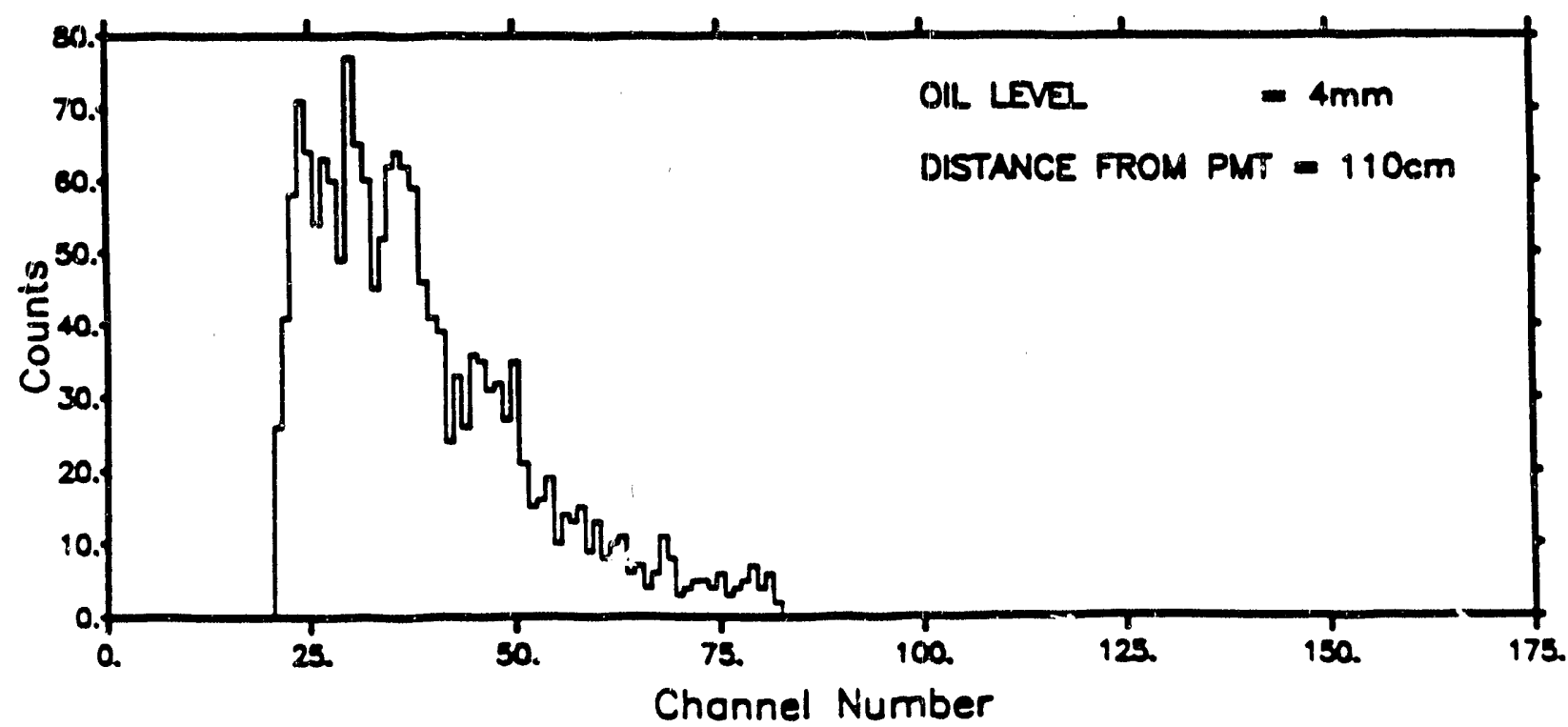


27

FIGURE 9

VARIATION OF LIGHT OUTS UN WITH OIL LEVEL
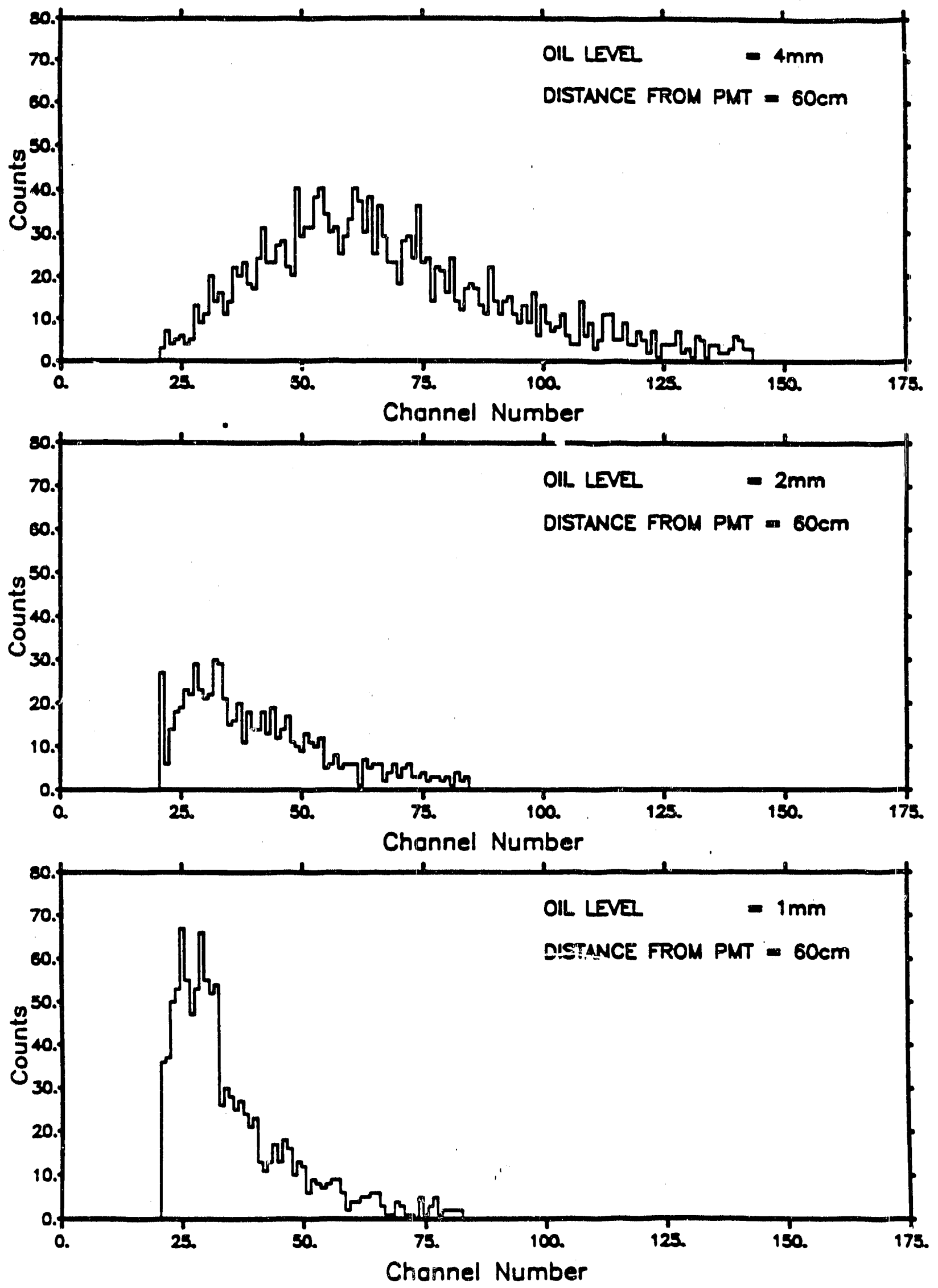
oil level. Since the energy loss is proportional to the number of photons produced, the average channel number should decrease.

3. The average channel number varied with each scintillator-fib naterial system as shown in Figure 10. This can be attributed to different absorption lengths of the oil, different reflection constants at the two mediums interfaces and because Teflon has a higher light collection due to the larger TIR.

In Table 2 and Table 3, the data indicates that light output varies with distance from PMT, oil level and scintillation oil-fiber material system used. The light output decreases as the oil level is lowered and decreases as the distance from the PMT increases. The light output is greater for the Tellon-Bicron system than it is for the GlassClad-MACRO system. 
29

FIGURE 10

VARIATION OF LIGHT OUTPUT WITH SYSTEM

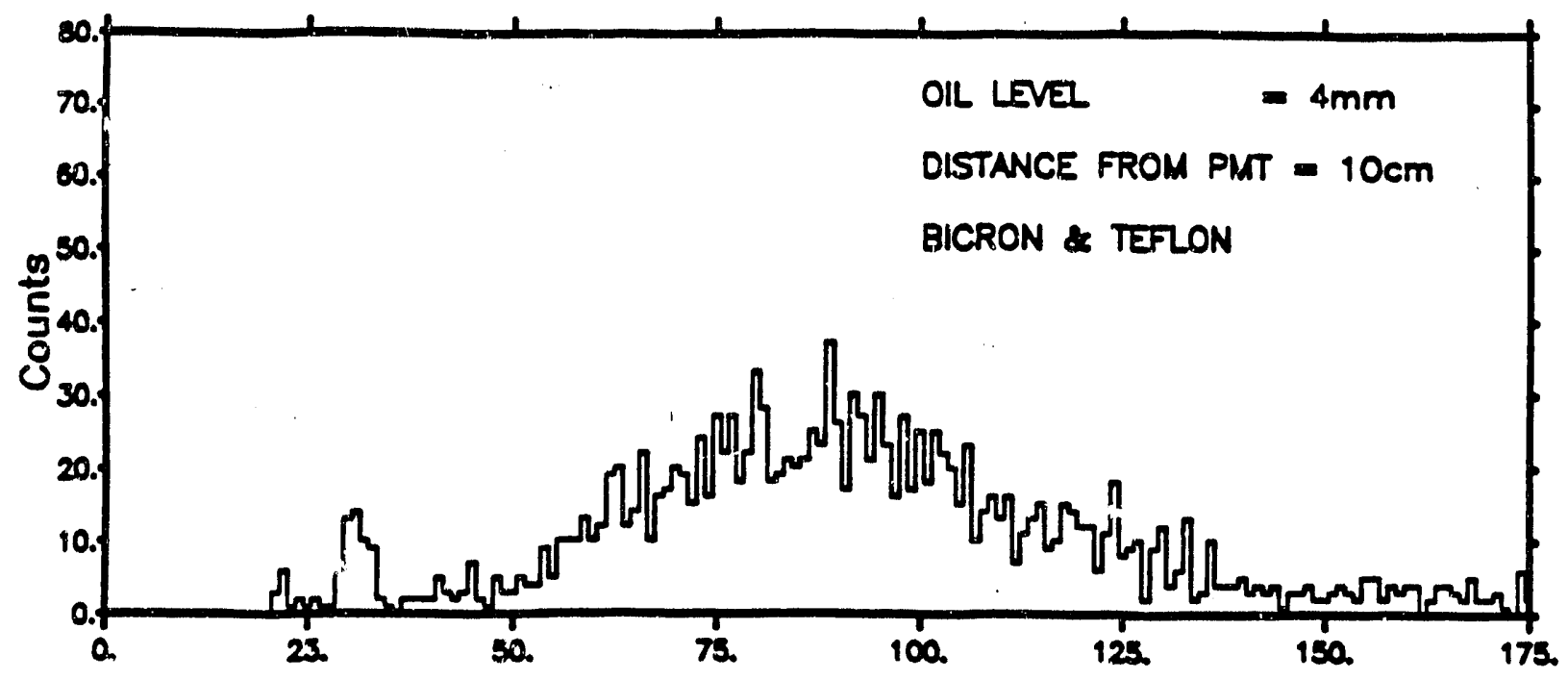

Channel Number

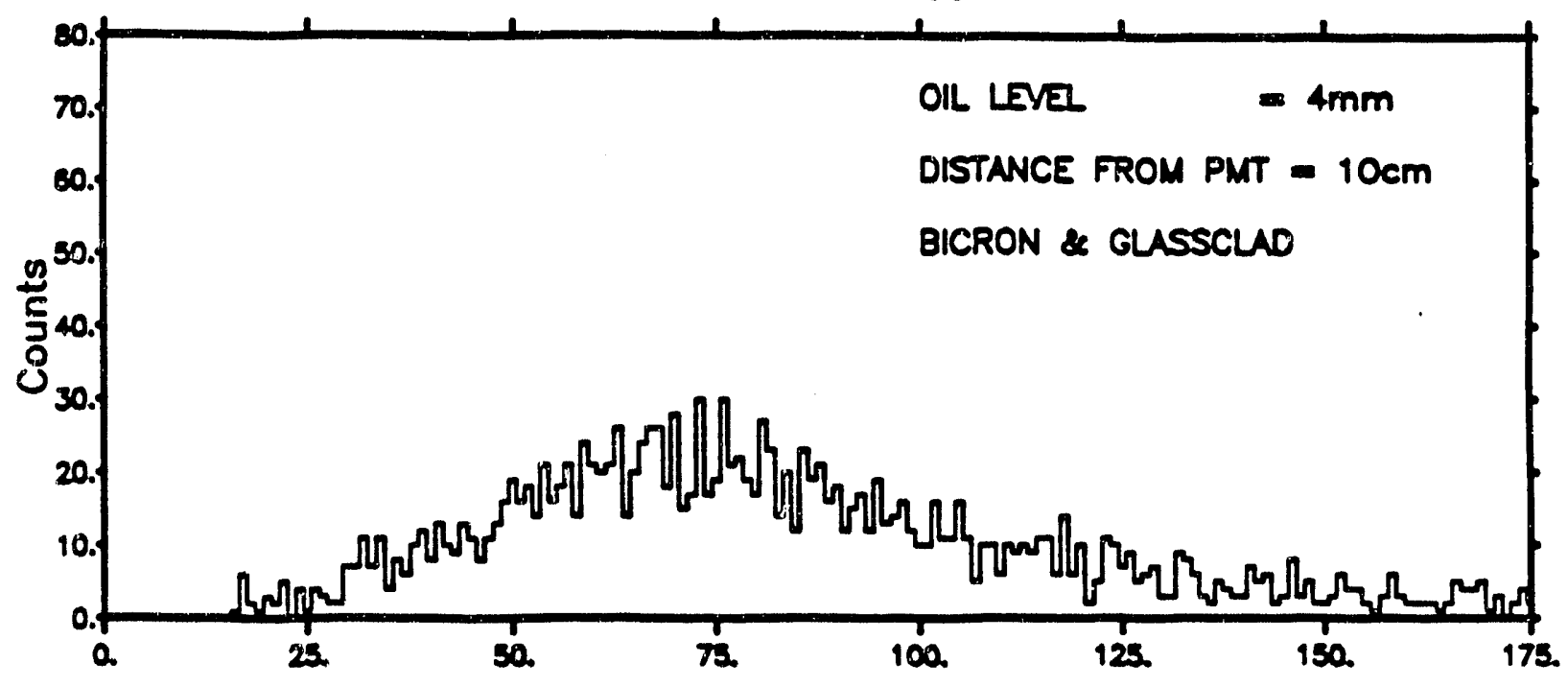

Channel Number

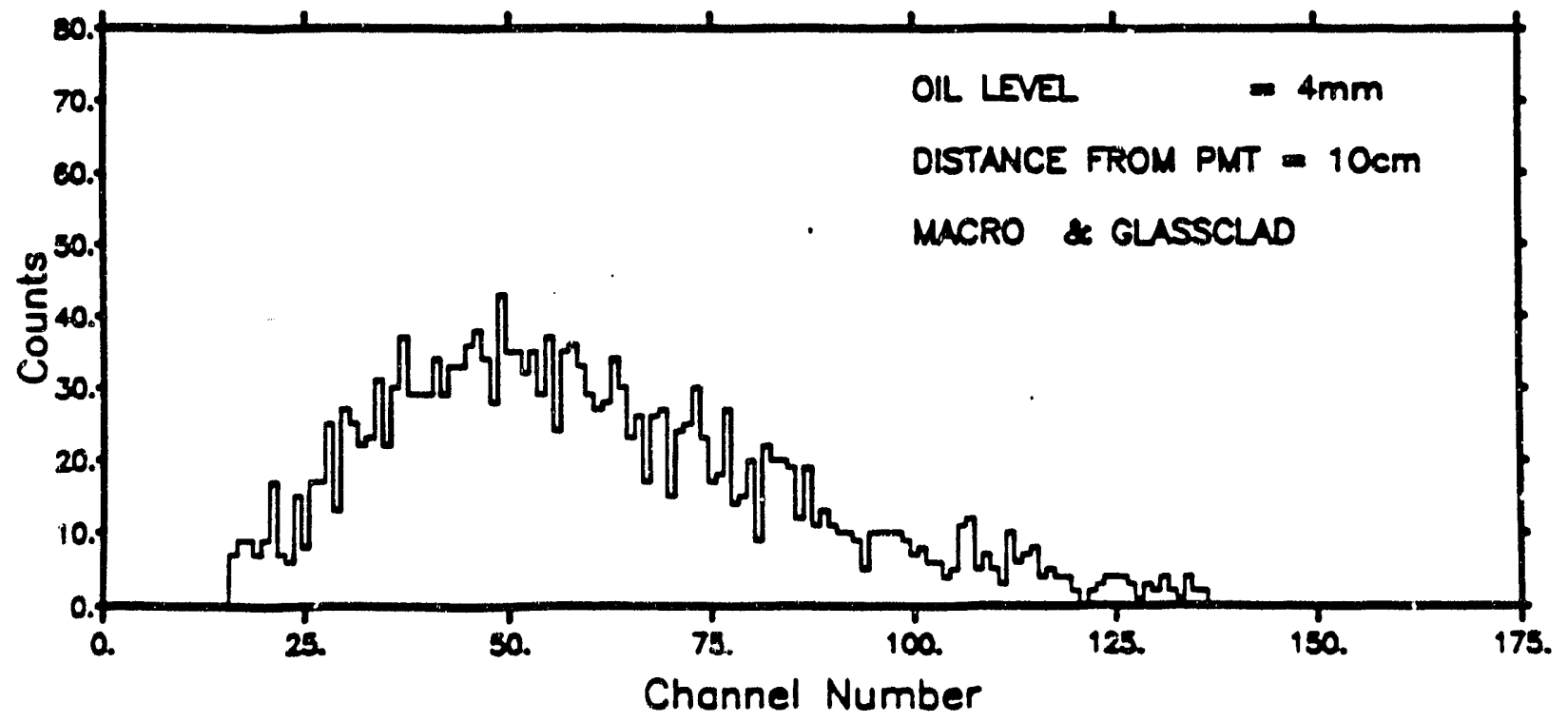


TABLE 2

LIGHT OUTPUT OF TEFLON-BICRON SYSTEM

\begin{tabular}{|c|c|c|}
\hline Oil Level (mm) & Distance $(\mathrm{cm})$ & Light Output (Pe) \\
\hline \multirow[t]{5}{*}{4} & 10 & $44.076 \pm 18.572$ \\
\hline & 35 & $19.902 \pm 9.368$ \\
\hline & 60 & $12.574 \pm 5.278$ \\
\hline & 85 & $8.712 \pm 5.051$ \\
\hline & 110 & $5.802 \pm 3.927$ \\
\hline \multirow[t]{5}{*}{3} & 10 & $23.097 \pm 9.340$ \\
\hline & 35 & $11.719 \pm 6.136$ \\
\hline & 60 & $8.081 \pm 4.653$ \\
\hline & 85 & $4.526 \pm 2.887$ \\
\hline & 110 & $3.150 \pm 2.146$ \\
\hline \multirow[t]{5}{*}{2} & 10 & $11.502 \pm 5.938$ \\
\hline & 35 & $5.024 \pm 3.273$ \\
\hline & 60 & $3.314 \pm 2.253$ \\
\hline & 85 & $2.163 \pm 1.432$ \\
\hline & 110 & $1.945 \pm 1.306$ \\
\hline \multirow[t]{5}{*}{1} & 10 & $7.408 \pm 4.497$ \\
\hline & 35 & $3.103 \pm 2.219$ \\
\hline & 60 & $2.408 \pm 1.873$ \\
\hline & 85 & $1.785 \pm 1.262$ \\
\hline & 110 & $1.621 \pm 1.079$ \\
\hline
\end{tabular}


TABLE 3

LIGHT OUTPUT OF GLASSCLAD-MACRO SYSTEM

\begin{tabular}{|c|c|c|}
\hline Oil Level (mm) & Distance $(\mathrm{cm})$ & Light Output (Pe) \\
\hline \multirow[t]{5}{*}{6} & 10 & $30.841 \pm 13.135$ \\
\hline & 23 & $17.631 \pm 11.450$ \\
\hline & 35 & $10.724 \pm 5.311$ \\
\hline & 60 & $7.135 \pm 3.872$ \\
\hline & 85 & $4.770 \pm 2.444$ \\
\hline \multirow[t]{5}{*}{4} & 10 & $13.834 \pm 7.494$ \\
\hline & 35 & $3.905 \pm 3.089$ \\
\hline & 60 & $2.715 \pm 2.093$ \\
\hline & 85 & $2.060 \pm 1.580$ \\
\hline & 110 & $1.940 \pm 1.428$ \\
\hline \multirow[t]{5}{*}{3} & 10 & $10.360 \pm 7.084$ \\
\hline & 35 & $2.397 \pm 1.975$ \\
\hline & 60 & $2.022 \pm 1.598$ \\
\hline & 85 & $1.701 \pm 1.125$ \\
\hline & 110 & $1.618 \pm 1.013$ \\
\hline
\end{tabular}

\subsection{Attenuation Length of Each System}

As a photon is propagated down the fiber, it has a chance to be absorbed by either the scintillation oil or by the fiber material. The attenuation length, $\lambda_{A}$, is the distance a photon travels before its energy is reduced by a factor of $e_{\text {. To put }}$ this in mathematical terms: 


$$
E=E_{0} e^{\frac{\varepsilon}{x}}
$$

where $E$ is the final energy, $E_{0}$ is the initial energy, $\lambda_{A}$ is the attenuation length, and $x$ is the distance the photon travels.

We initially believed that the attenuation length, $\lambda_{A}$, was independent $\left(v^{\prime \prime}\right.$ the height of the scintillation oil and was only characteristic of a scintillation oilfiber material system. However, our data appears to indicate that the attenuation length does change with height of the scintillation oil.

As indicated earlier in this report, the number of photors detected by a PMT at a certain distance away is related this way:

$$
E=E_{0} e^{\left(\lambda_{1}^{2}\right)}
$$

An alternate way of expressing this equation is:

$$
\lambda_{A}=\frac{\Delta x}{\ln \left(\frac{E_{\varepsilon}}{E_{e+\Delta x}}\right)}
$$

In the analysis of the attenuation length, we used the distances of $60 \mathrm{~cm}, 85$ $\mathrm{cm}$, and $110 \mathrm{~cm}$, because the data between these points appeared to be linear. See Figures 11 and 13. We used a linear regression program that is built into a calculator (HP-28S) to fit these three points and then calculated the error through propagation of error. The attenuation length is the inverse of the slope of the line generated graphed on a distance from PMT vs. natural log of the number of photoelectrons. 

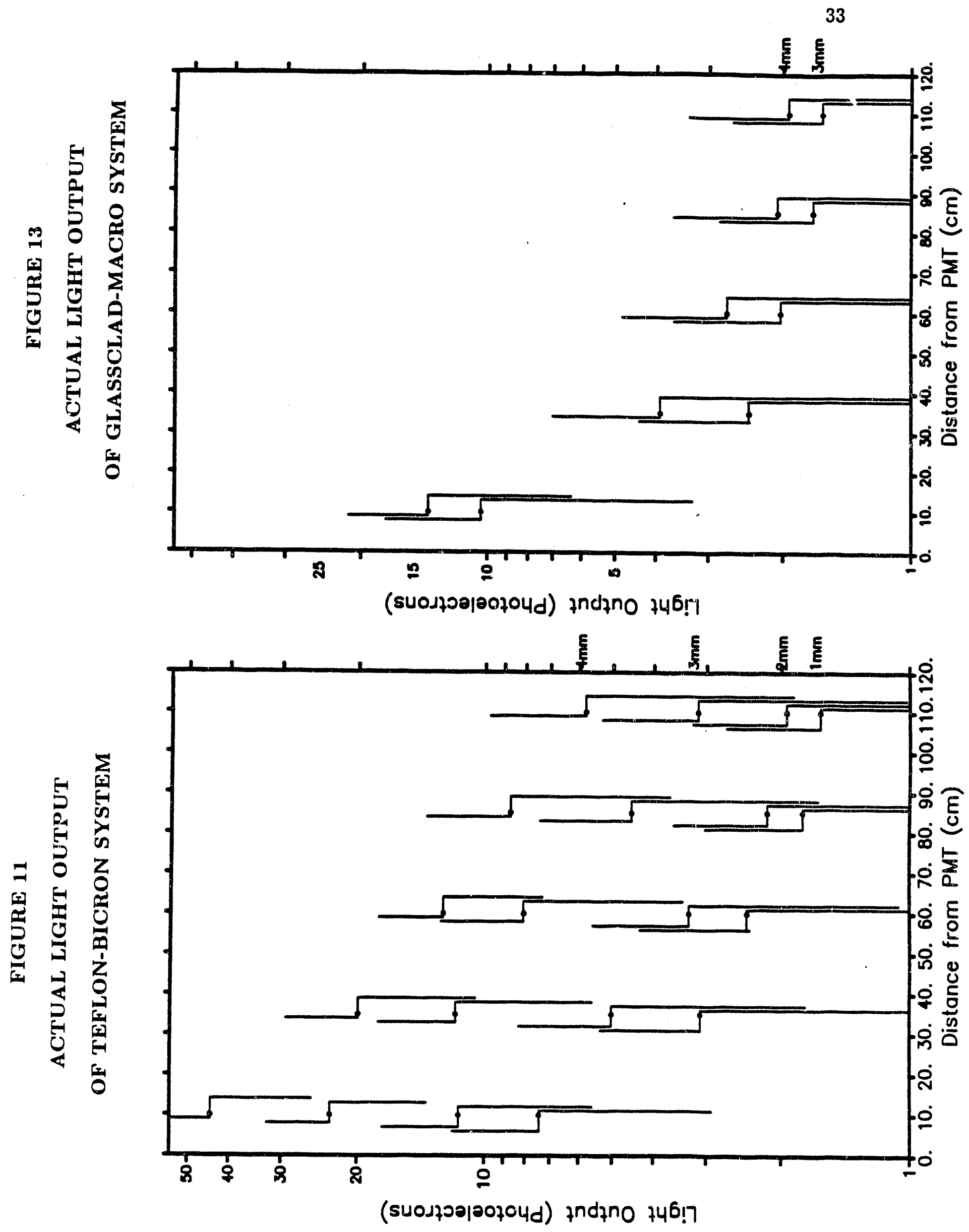
The results were curious. The measured attenuation length appeared to increase as the oil level decreased. Table 4 indicates the attenuation lengths measured for each system with their respective deviations:

TABLE 4

ATTENUATION LENGTH OF EACH OIL LEVEL

\begin{tabular}{|c|c|c|}
\hline System & Oil Level (mm) & Attenuation Length(cm) \\
\hline Teflon & 4 & $64.599 \pm 9.414$ \\
$\&$ & 3 & $53.022 \pm 7.106$ \\
Bicron & 2 & $91.743 \pm 23.793$ \\
Oil & 1 & $90.580 \pm 46.220$ \\
\hline GlassClad & 6 & 61.73 \\
$\&$ & 4 & $148.810 \pm 66.719$ \\
MACRO & 3 & $224.215 \pm 143.498$ \\
Oil & & \\
\hline
\end{tabular}

For each of the systems measured, the attenuation length increased for lower oil levels. This increase in attenuation length for low oil levels could occur because at low oil levels, the PMT is at the one photoelectron. The light output levels out at one photoelectron; so, the attenuation length, which is dependent on the quotient of the light output of two different distances, would naturally increase as the light outputs approach each other.

The attenuation length of the Tellon-Bicron system at $4 \mathrm{~mm}$ oil level is $64.599 \pm 9.414 \mathrm{~cm}$. This length decreased for the $3 \mathrm{~mm}$ oil level. The decrease in 
the attenuation length at this level is probably due to an increase in the average number of times photons contact a boundary. At the $2 \mathrm{~mm}$ and $1 \mathrm{~mm}$ oil level, the attenuation length increases. This is probably because the light output at these oil levels is at the one photoelectron level. The only attenuation lengths that are calculatable to any reasonable degree of accuracy are the $3 \mathrm{~mm}$ and $4 \mathrm{~mm}$ oil levels of the Teflon-Bicron system. The attenuation length at these oil levels are on the order of $50-75 \mathrm{~cm}$.

The GlassClad-MACRO system reduced to the one photoelectron level very rapidly for oil levels $4 \mathrm{~mm}$ and lower. The attenuation length measured at the $4 \mathrm{~mm}$ oil level was about 1.5 meters. This attenuation length may be higher than the actual attenuation length, because the data at these points are close to the one photoelectron. Because of this reduction to the one photoelectron level, we took another reading at the $6 \mathrm{~mm}$ oil level. The result of this new data run resulted in an attenuation length of $61.73 \mathrm{~m}$. This is consistent with the Teflon's attenuation length.

\subsection{Total Light Output for Each System}

To measure the total light output for a system, we first need to set a standard distance from the PMT to count the number of photoelectrons. The distance this standard is $0 \mathrm{~cm}$ from the PMT. To calculate the number of photoelectrons at $0 \mathrm{~cm}$ we use the same linear regression program that is built into the HP-28S calculator. See Figures 11 and 13 on page 33. The number of photoelectrons at $0 \mathrm{~cm}$ is $e$ raiscd to the $y$-intercept. Table 5 shows the variation of light output at various oil levels of each system. 
TABLE 5

LIGHT OUTPUT OF EACH OIL LEVEL

\begin{tabular}{|c|c|c|}
\hline System & Oil Level $(\mathrm{mm})$ & Light Output at $0 \mathrm{~cm}(\mathrm{Pe} / \mathrm{mm}$ of oil) \\
\hline Teflon & 4 & $8.010 \pm 1.167$ \\
$\&$ & 3 & $8.056 \pm 1.080$ \\
Bicron & 2 & $2.040 \pm 0.529$ \\
Oil & 1 & $3.494 \pm 1.783$ \\
\hline GlassClad & 6 & 3.147 \\
\& & 4 & $0.980 \pm 0.439$ \\
MACRO & 3 & $0.647 \pm 0.414$ \\
Oil & & \\
\hline
\end{tabular}

The data shows that for the Teflon-Bicron system at the $4 \mathrm{~mm}$ and $3 \mathrm{~mm}$ oil level, the light output at $0 \mathrm{~cm}$ is about 8 photoelectrons per $\mathrm{mm}$ of oil. For the $2 \mathrm{~mm}$ and $1 \mathrm{~mm}$ oil level, the light output at $0 \mathrm{~cm}$ decreased to about 2 and 3.5 photoelectrons respectively. This inconsistency may be due to the fact that the light output at these oil levels were at the one photoelectron level.

For the GlassClad-MACRO system, the light output at $0 \mathrm{~cm}$ was on the order of 3 photoelectron for the $6 \mathrm{~mm}$ reading. The 4 and $3 \mathrm{~mm}$ readings had a light outpui close to I photoelectron. This could be because the light output at the two oil levels measured were at the one photoelectron level. 


\subsection{COMPUTER SIMULATION PROGRAM}

\subsection{General Features}

The computer simulation program Simulation.for (see Appendix E) design is to analyze the data and attempt to predict:

1. The acceptability of the data produced by each run.

2. The approximate reflection constant of the fiber material (what percent of light is reflected each bounce).

3. The attenuation length of the scintillation oil.

To complete this task, Simulation.for generates random muons that interact with scintillation oil to generate photons. These photons propagate down the interior of a detector to a PMT.

The exact specifications of Simulation.for are as follows:

\subsubsection{Initial Parameters}

1. Width of Detector $(10 \mathrm{~cm})$

2. Number of Photons Produce per rmm of Oil (10000)

3. TIR of Water $\left(42.435^{\circ}\right)$

4. TIR of Teflon $\left(26.000^{\circ}\right)$

5. TIR of GlassClad $\left(17.000^{\circ}\right)$

\subsubsection{Variable Parameters}

1. Height of Oil

2. Distance from PMT

\subsubsection{Predicted Parameters}

1. Absorption Length of Oil 
2. Percent Reflected from Teflon Surface

3. Percent Reflected from GlassClad Surface

With these entered, Simulation.for automatically does the following:

\subsubsection{Random Variables}

1. Height in the Scintillator

2. Distance of Event from the Left Side of the Detector

3. Direction of the Photon

\subsubsection{Ray Tracing}

1. Calculates the Angle of a Photon Incident on any of the Four Surfaces (Water, Coating, or the two Teflon Sides).

A. If the angle is less than the TIR, the program allows the ray to bounce.

B. If the angle is greater than the TIR, the program checks Fresnal's equations to see if the photon is reflected.

2. Checks to see if any light is absorbed by the scintillator.

3. Checks the reflection constant for each bounce.

4. Counts all photons that are detected by the PMT,

\subsubsection{Output}

1. Number of Photons Detected (Light Output)

2. Percent of Photons Detected

3. Standard Deviation

One needs only to compare the simulated data to the actual data to find the absorption length of the scintillation oil and the reflection constants of the fiber 
materials. The method we used to compare the simulated data to the experimental data is:

1. Set the light output of the simulated data at $60 \mathrm{~cm}$ from PMT and $4 \mathrm{~mm}$ oii height to the measured light (utput at that same point and adjust the other simulated light output accordingly.

2. Adjust the absorption length and the reflection constants to get approximately the same attenuation length for the $4 \mathrm{~mm}$ oil level. The comparisons are all done visually

\subsection{Results of Simulation}

5.2.1 Teflon-Bicron The simulated light output fit remarkably well to the measured output at the $4 \mathrm{~mm}$ oil level. The $3 \mathrm{mrn}, 2 \mathrm{~mm}$ and $1 \mathrm{~mm}$ oil levels did not compare as nicely, but were certainly within the limits of the standard deviation. See Figures 11 and 12.

The apparent absorption length of the Bicron BC-517 Scintillation Oil is predicted to be 1.0 meter. This is approximately a factor of ten less than the advertised attenuation length. The predicted percent of light reflected from the Teflon Surface after each bounce is $97.0 \%$.

5.2.2 GlassClad-MACRO This system was a little easier to simulate since the MACRO oil has been well tested and the absorption length is known to be $\geq$ $10.0 m^{[8]}$. The visual comparison of the simulated data to the measured output was not as precise as that of the Teflon-Bicron system. The measured light output had a sharper increase in light output at distances close to the PMT than the simulation program could obtain. The actual light output measured at the lower oil levels 
did not agree with the data obtained by the simulation program. The reflection constant calculated for the GlassClad by the simulation program is $98.0 \%$. See Figures 13 and 14. Because the data for the $6 \mathrm{~mm}$ reading was just taken, the simulation for this oil level has not been completed. 

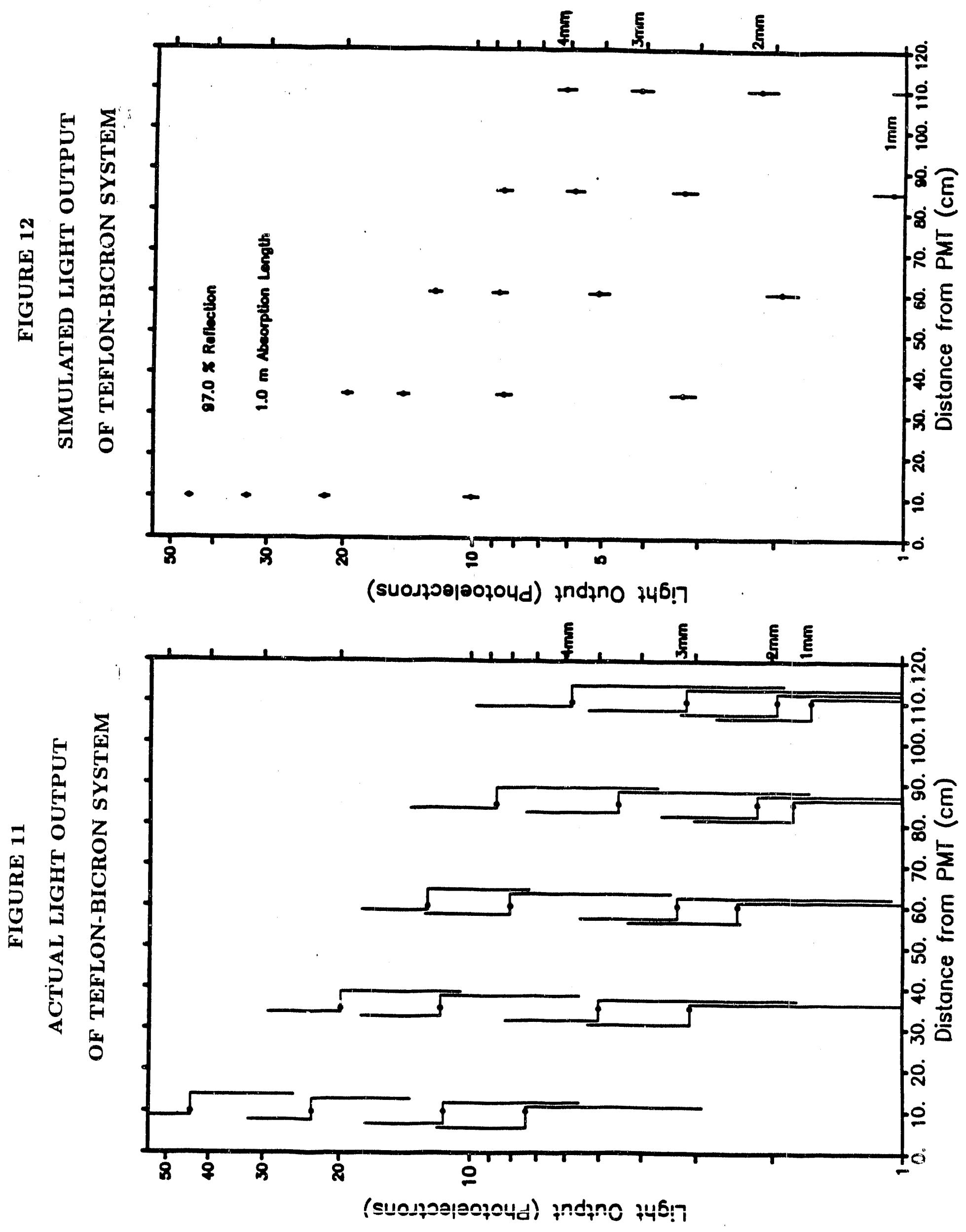

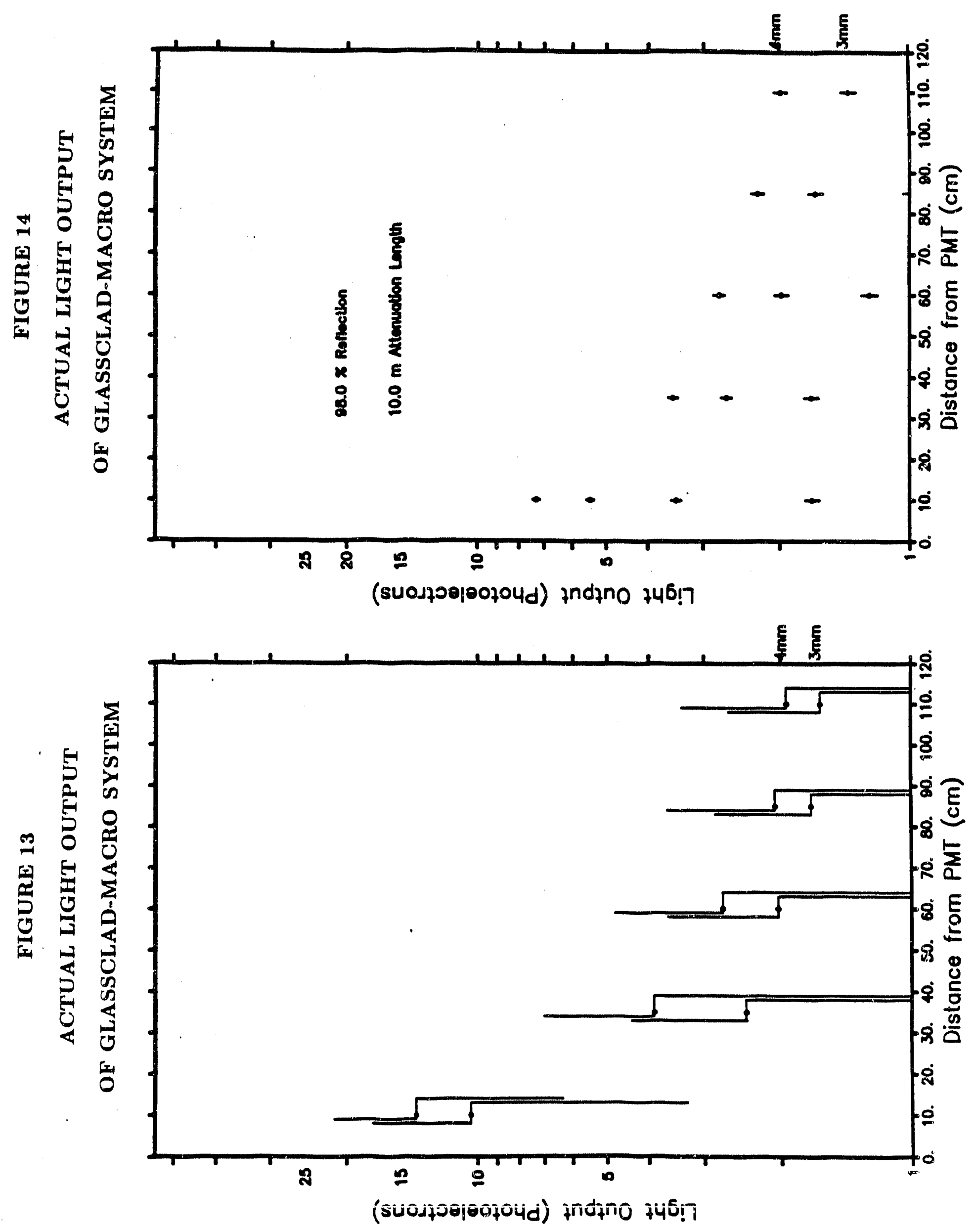


\subsection{CONCLUSION}

For the Teflon-Bicron system, the attenuation length measured for the oil levels of $4 \mathrm{~mm}$ and $3 \mathrm{~mm}$ is between $0.645 \pm 0.094-0.530 \pm 0.071$ meters, and the light output at $0 \mathrm{~cm}$ from the PMT is $\sim 8.01 \pm 1.10$ photoelectrons per mm of oil. The attenuation lengths increased and the light output per mm of oil decr ased for the $2 \mathrm{~mm}$ and $1 \mathrm{~mm}$ oil levels. This could be attributed to the fact that the light output at these levels are around one photoelectron. . According to the simulation program, the Bicron BC-517 oil has an absorption length of $1.0 \mathrm{~m}$ and the Teflon surface reflects $97.0 \%$ of the light at angles less than the TIR angle of $26^{\circ}$.

For the GlassClad-MACRO system, the attenuation length measured was $1.488 \pm 0.667$ meters for the $4 \mathrm{~mm}$ oil level and $2.242 \pm 1.435$ meters for the $3 \mathrm{~mm}$ oil level. The light output at $0 \mathrm{~cm}$ measured for these oil levels was $0.980 \pm 0.439$ $\mathrm{Pe} / \mathrm{mm}$ of oil for the $4 \mathrm{~mm}$ oil level and $0.647 \pm 0.414 \mathrm{Pe} / \mathrm{mm}$ of oil. These results could be inaccurate because both of the oil levels have light output on the one photoelectron level. Because of this, we took an extra data run at the $6 \mathrm{~mm}$ oil level. The results of this run show the attenuation length was $\sim 61.73 \mathrm{~m}$ and the light output at $0 \mathrm{~cm}$ was $\sim 3.15$ photoelectrons. The simulation program indicates that the reflection constant of the GlassClad is $98.0 \%$. The absorption length of the MACRO oil is known to be 10.0 meters. The TIR of the GlassClad is $1.7^{\circ}$ and the refractive index is 1.415 .

\subsection{Results of Measurement and Simulation}

\subsection{Suitability for Use in Caiorimeter Construction}

The minimum attenuation length necessary for a calorimeter is about $2 \mathrm{~m}$. Both systems, the Teflon-Bicron and the GlassClad-MACRO, have attenuation 
lengths which are close enough to warrant further investigation.

The number of photoelectrons necessary for a reasonable electromagnetic resolution at $4 \mathrm{G} r$ was previously calculated to be 177 photoelectrons. The energy loss of a muon traveling through scintillator was calculated to be $0.2012 \frac{\mathrm{MeV}}{\mathrm{mm} \text { of oil }}$. Converting the number of photoelectrons at $4 \mathrm{GeV}$ to the number of photcielectrons liberated when a muon passes through a mm of oil, we obtain 0.009 photoelectrons per mm of oil. Both detectors produced many more photoelectrons than this, indicating that both materials could possibly be suited for use in a calorimeter.

\subsection{Further Items to Study}

It will be necessary to obtain clearer data from both GlassClad systems. The data from the GlassClad-Bicron system was inconsistent. The light output for this system should be remeasured to see if there was a systematic error in this data that caused the inconsistent data. Also, one should run some tests on a Teflon-MACRO system tc see how the light output compares with the other three systems.

The next step is to test these components for their sensitivity to radiation. It is necessary to see if any visible damages occur. After this initial inspection, one needs to see if the attenuation length, light output, reflection constant or the absorption length varies with high radiation dosages. 


\subsection{REFERENCES}

1. R. C. Webb, et. al., Proposal to Investigate a Liquid Scintillator Alternative to Scintillating Fiber Calorimetry for the SSC, Physics Department, 'Texas A\&M aiversity, 1989.

2. D. Perkins, "Introduction to High Energy Physics, $3^{\text {rd }}$ Edition" Meulo Park: Addison-Wesley Publishing Company, Inc., 1987.

3. M. Gilchriese, "Detector Research and Development for Experiments at the Superconducting Super Collider," Collider Physics: Current Status and Future Prospects, Nashville, October, 1987.

4. W. Leo, "Techniques for Nuclear and Particle Physics Experiments," SpringerVerlag : Berlin, 1987.

5. J. Gaillard, "Tracking with Scintillating Fibres," Proceedings of the XXIV International Conference on High Energy Physics, Munich, August, 1988.

6. Bicron Oil BC-517L is a product of Bicron Corporativn.

7. MACRO Oil, This custom scintillating oil mixture is being used in a large underground cosmic ray experiment at the Gran Sasso Laboratory, L'Aquila, Italy. The composition of this mixture is 6\% Pseudocumene, 99\% Mineral Oil, $0.9 \%$ PPO, and $0.1 \%$ Bis-MSB.

8. Teflon is a Reg. TM of E.I. DuPont Co.

9. GlassClad PS-252 Petrarch FF is a product of Petrarch Systems Silanes \& Silicones.

10. Paraffin Jil 0-122 is a product of Fisher Scientific.

11. "Review of Particle Properties," Physics Letters B204, Ápril, 1988.

12. R. Weast, "Handbook of Chemistry and Physics," Chemical Rubber Co., Cleveland, 1970. 
APPENDIX A

PROPOSAL

\section{A STUDY OF LIQUID SCINTILLATOR AND FIBER MATERIALS FOR THE USE IN A FIBER CALORIMETER}

A Proposal

by

Peter Parker Altice Jr.

Submitted to Elizabeth Tebeaux

Texas A\&M University

March 7, 1990 


\title{
TEXAS A\&M UNIVERSITY \\ DEPARTMENT OF PHYSICS \\ COLLEGE STATION, TEXAS 77843-4242 \\ Phone: (409) 845-7844 \\ Fax: (409) $845-2590$
}

April 17, 1990

\begin{abstract}
TO: $\quad$ Elizabeth Tebeaux
FROM: Peter Parker Altice, Jr.

SUBJECT: Proposal for Formal Report
\end{abstract}

\section{TENTATIVE TITLE}

A Study of Liquid Scintillator and Fiber Materials for the Use in a Fiber Calorimeter

\section{SUMMARY}

I propose to write my formal report on the topic of liquid scintillators and fiber materials. The paper will discuss the testing of these materials, as well as briefly describe their uses. My experience in working with liquid scintillator calorimeters should provide valuable information. By writing this report, I hope to show high energy physicists that further study of liquid scintillator should be done. My report will coincide with my Fellows Research Project. The estimated cost for my research and writing my report is $\$ 3,525.50$.

\section{PROJECT DESCRIPTION}

With the Superconducting Super Collider (SSC) less than a decade away, scientists and engineers are already striving for new advances in technology in the 
felds of superconductivity, computers, data acquisition, and detector development in support of experiments being planned for this facility. At Texas A\&M one of the fields of research being studied is that of $R \& D$ for detection devices. Currently, most high energy accelerators use magnetic spectrometry to detect high energy particles; however, recent research in calorimetric techniques suggest that a calorimeter (total energy absorbing detector) could out perform magnetic spectrometry at the higher energies expected at the SSC. While many of the calorimetric techniques work well at the energies currently available, more research and development is needed for SSC energies. High energy physicists at Texas $A \& M$ are now researching liquid scintillators to design a scintillating fiber calorimeter. I propose to test liquid scintillating material and fibers planned for use in these devices. These tests are crucial for setting up the design of a calorimeter suitable for use at the SSC.

The research being done on fiber calorimetry at Texas A\&M has some unique characteristics. First, the fibers are filled with liquid scintillator. This has advantages over plastic scintillators due to the flexibility of liquid scintillators and the wide variety of liquid scintillators currently on the market. Second, the fibers proposed would provide a totally internal reflecting channel. The channels are coated with a thin (Teflon or Glass Clad.PS 252) film to provide total internal reflection for the light emitted by the liquid scintillator. This will reduce the amount of light lost during the hadronic shower cascade thus making them as good as solid fibers.

My research will involve testing two scintillating oils, Bicron and MACRO, and two fiker materials, Teflon and Glass Clad-PS 252, for refraction index, attenuation length, and overall performance. I will then write a paper describing 
these tests and analyzing their data. From this analysis I will discuss the construction of a fiber calorimeter prototype.

\section{PROJECT PLAN}

\section{Scope}

The purpose of this report is to provide a knowledge of the testing and uses of liquid scintillator and fiber materials. Because the purpose is somewhat broad, I will test only two liquid scintillators, Bicron and MACRO, and two fiber materials, Teflon and Glass Clad-PS 252. My goal is to discover which scintillator oil and what fiber material is the best suited for use in a fiber calorimeter. Due to lack of timing, my testing will not include radiation hardness. I will end my report with a discussion of a possible fiber calorimeter prototype.

\section{Task Breakdown}

The following schedule lists the tasks necessary to complete my formal report:

$$
\text { Task } \quad \text { Schedule (days) }
$$

1. Research

2. Analyze sources

3. Write first draft

4. Revise and rewrite

5. Create charts and attachments

6. Proofread and make changes

7. Type and correct

8. Bind and copy 


\section{Tentative Outline}

I. Introduction
A. Purpose and audience
B. Definitions
C. Sources
D. Scope

II. Testing of scintillation oil and fiber materials
A. Index of Refraction
B. Attenuation length
C. Overall Performance

III. Analysis of data
A. Efficiency of each system
B. Absorption constant of each oil
C. Total light output of each system

IV. Design of a liquid scintillator calorimeter

V. Conclusion 


\section{PERSONNEL QUALIFICATIONS}

My qualifications for discussing the topic are my previous experience with particle detectors and my interest in physics. For the past two years I have been a member of the High Energy Physics Research group (HEPR) here at Texas A\&M. I spent the last two semesters working with two different liquid scintillator detectors and have become very familiar with their operation and design. While my coursework is not as strong as it will be, I believe that my knowledge, gained through "hands-on" experience, will be more than adequate for this report.

\section{FACILITIES}

To gain necessary data, I plan to use the following resources:

1. High Energy Research Laboratory at Texas A\&M

2. $\underline{H E P R}$ MicroVMS computer system

3. Scholarly journals

4. Equipment manuals

5. Interview with Doctor Robert Webb, professor, Physics, Texas A\&M University 


\section{Costs}

The following list presents estimated costs for report preparation:

Item $\quad$ Amount

1. Labor

a. Research ( 200 hours at $\$ 13.50 /$ hour )* $\$ 2,025.00$

b. Writing ( 50 hours at $\$ 13.50 /$ hour )* $\$ 675.00$

2. Building the detector

$\$ 700.00$

3. Scintillation oil and fiber materials

$\$ 100.00$

4. Paper ( 100 sheets )

$\$ \quad 4.50$

5. Copying

$\$ \quad 6.00$

6. Bonding

$\$ \quad 5.00$

7. Miscellaneous

$\$ 10.00$

TOTAL

$\$ 3,525.50$

* Based on estimated yearly salary of $\$ 25,000.00$ for a consultant.

\section{CONCLUSION}

In closing, I would like to stress the importance of designing and building an improved detector for the SSC. The fiber calorimeter with liquid scintillating material could be the detector of the future. However, before this new detector can be built, the fiber materials and liquid scintillator must first be tested and evaluated for their suitability in such a detector. Research into liquid scintillators and fiber calorimeters is important for the development of the next generation of experiments for use at the SSC. 


\section{REFERENCES}

1. Bicron Oil BC-517L is a Reg. TM of Bicron Corporation.

2. Glass Clad PS-252 Petrarch FF is a Reg. TM of Petrarch Systems Silanes \& Silicones.

3. MACRO Oil, This custom scintillating oil mixture is being used in a large underground cosmic ray experiment at the Gran Sasso Laboratory, L'Aquila, Italy. The composition of this mixture is $6 \%$ Pseudocumene, 99\% Mineral Oil, $0.9 \%$ PPO, and $0.1 \%$ Bis-MSB.

4. D. H. Perkins, Introduction to Figh Energy Physics, grd Edition, AddisonWesley Publishing Company, Inc., 1987.

5. Teflon is a Reg. TM of E.I. DuPont Co.

6. R. C. Webb, et. al., Proposal to Investigate a Liquid Scintillator Alternative to Scintillating Fiber Calorimetry for the SSC, Physics Department, Texas A\&M University, 1989. 


\title{
APPENDIX B 'PROGRESS REPORT
}

\section{A STUDY OF LIQUID SCINTILLATOR AND FIBER MATERIALS FOR THE USE IN A FIBER CALORIMETER}

\author{
A Progress Report \\ by \\ Peter Parker Altice Jr. \\ Submitted to Elizabeth Tebeaux \\ Texas A\&M University
}

April 13, 1990 


\section{TEXAS A\&M UNIVERSITY \\ DEPARTMENT OF PHYSICS \\ COLLEGE STATION, TEXAS 77843-4242 \\ Phone: (409) 845-7844 \\ Fax: (409) 845-2590}

April 17, 1990

TO: Elizabeth Tebeaux

FROM: $\quad$ Peter Altice Jr.

SUBJECT: Progress Report on Formal Report

\section{PURPOSE OF MEMO}

The purpose of this memo is to inform you on the state of completion of my formal report. As you know, my report deals with the testing of scintillation oil and fiber material for their suitability in a liquid scintillator fiber calorimeter.

\section{SUMMARY}

As of April 1, I have completed all of the research necessary for report. I have written my first draft, created tables and graphs for my report and rewritten a second draft. I am currently proofreading my formal report and making all necessary changes. After this final proofing, I will bind the report and submit it to you. My total incurred cost have presently reached $\$ 3,388.50$ of the $\$ 3,525.50$ estimated total cost. 


\section{STATUS OF WORK}

Work Completed

Task 1. Research

Task 2. Write first draft

Task 3. Create tables and graphs

Task 4. Write second draft

Work in Progress

Task 5. Proofread and make changes

Work remaining

Task 6. Bind and copy

\section{COST TO DATE}

1. Labor

a. Research ( 200 hours at $\$ 13.50 /$ hour ) $\$ 2,025.00$

b. Writing ( 45 hours at $\$ 13.50 /$ hour )* \$ $\$ 607.50$

2. Building the detector

$\$ 700.00$

3. Scintillation oil and fiber materials

$\$ 100.00$

4. Paper ( 1000 sheets )

* Based on estimated yearly salary of $\$ 25,000.00$ for a consultant. 


\section{REVISED OUTLINE}

I. Introduction

A. General Background

B. Principles of Calorimetry

C. Purpose

D. Research Plan

II. Design of a liquid scintillator calorimeter
A. Detector properties and construction
B. Electronics

III. Testing
A. Refractive index
B. Calibration of the QVT
C. Light Output

IV. Analysis of data
A. Systematic errors in data
B. Analysis of pulse height distribution
C. Attenuation length of each system
D. Total light output for each system

V. Computer simulation program
A. General features
B. Results of simulation

VI. Conclusion
A. Results of measurement and simulation
B. Suitability for use in calorimeter construction
C. Further items to study 


\section{CONCLUSION}

I am slightly ahead in the activities set forth on my $\because$ oject schedule and should easily make the April 23 deadline. I am currently devoting all of my time to the completion of this report. I still need to write the forward, summary and letter of recommendation. $\mathrm{My}$ final drast should be completed early next week, and then I can have copies made and bound. 


\title{
APPENDIX C
}

\author{
DPuiert Roun $(4+1,0-2)$ \\ Rolas x(3:0),y(3.0) \\ DDVETON A(30) $.8(300)$ \\ OAmereine defi \\ C \\ parcecter(oteventw .ex-14)

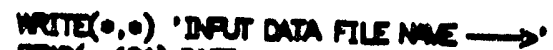

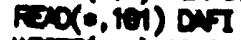

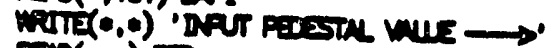 \\ $\mathrm{FOO}(0,0) \mathrm{FED}$

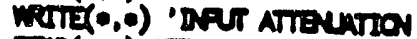 \\ FTO $(0, \oplus)$ ATT \\ wite $(0,102) d 0$ of \\ ien fonot (ai) \\ 16. Fomet (2x, "For date flle $, \cdot, \infty)$ \\ if (date(ott).1t.1.ed-14) ot t-1.ed-14

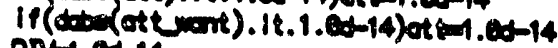 \\ DNm-1.9-14 \\ Svm.exp

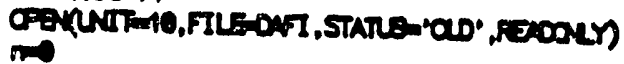 \\ $\infty 10 \mathrm{kH}, 3$ \\ RJO(10, $*, 00-0.0) \times(1), Y(1)$ \\ E(I) \\ AlI $(X(1)+D)$ an (AT \\ suanu(I) re(I) \\ DNonme(I) \\ nonts \\ 16 DNTre \\ 29.2 Meayon

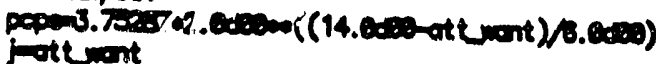 \\ 100 wite $(0,194)]$

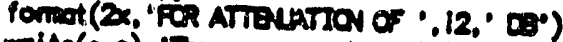

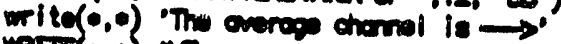

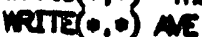 \\ wite( 0,0$)$ Thi overos PE la \\ wite-0.0) overpos

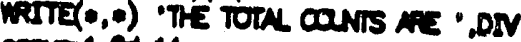 \\ cound.ex-14 \\ to $1601 \mathrm{in}, \mathrm{n}$

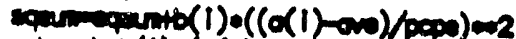 \\ 1901 \\ contine \\ or-1.deq(div-1.ex) \\ oven-d.dar(dir-1.co) won \\ drant (vor) \\ ondrart (over) \\ wite(e,16e2) ver \\ wlteco, 1600 dov \\ vrite(0, 1eans) don \\ onout (Ex. iverietien

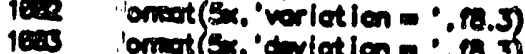 \\ 1824 iomat (Ex, chamel dom, fo.J) \\ STOP \\ 0
}

AVG.FOR 


\section{APPENDIX D}

\section{SIMULATION.FOR}

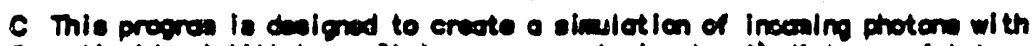

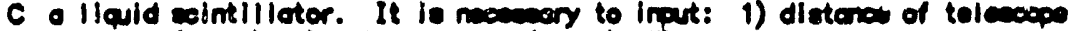

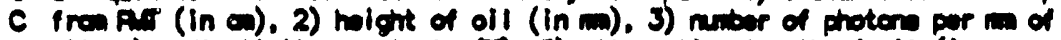

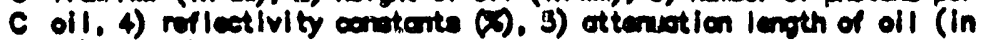

C n). and 8) TR of totien.

C

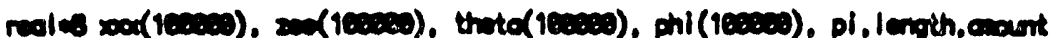

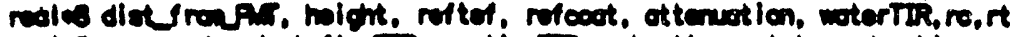

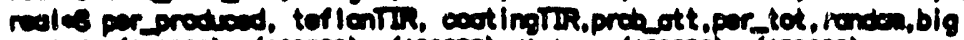

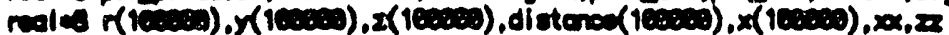

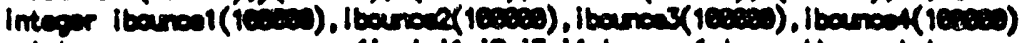

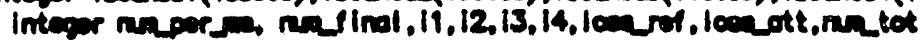

c chereterm def i

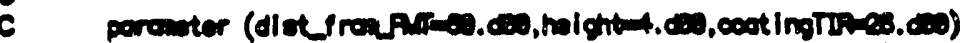

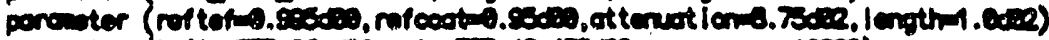

C

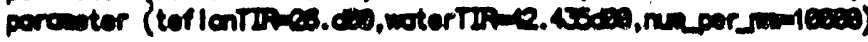

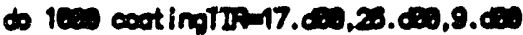

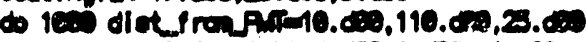

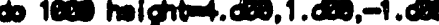

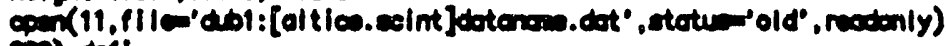

nex(11.20) dofl

foriot (ow)

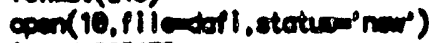

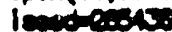

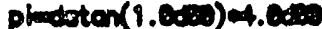

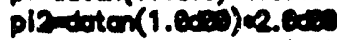

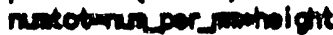

nefinato

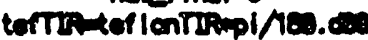

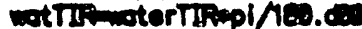

lom mite

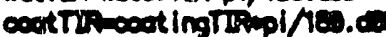

leosertos

120
120
$13-0$

C

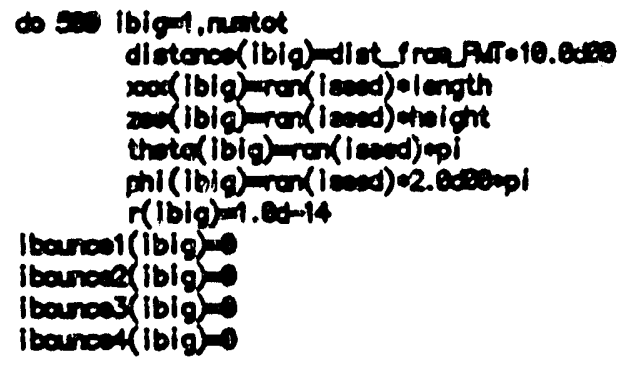

$c$

C This is the progren that thet toots coch side and beences. Side 1 and

C side 2 are the teflon cooted sides, alde 3 is the woter, ond elde 4 le

C tho cooting on the botton.

C

c

Sice 1

If (oni(ibia).g.1.04-14.end.phi(ibig).1t.piz) then oanlength-oox $(1 b / g)$ $y($ iblo $)$ dton(phi(ibig))

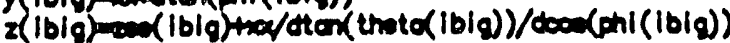

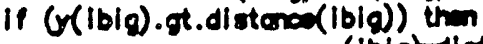
$y$ (ibig) distanoo( $(i b i g)$

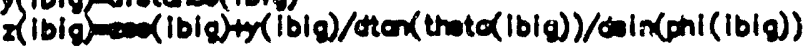


C teet TRR angle

$c$
C
C
2

C teot TR ongle

C

C

c

$C$ tect TR ongle

\section{endif}

If (x/bia).ot.holght) woto 3

if (z(ibig). it.1.ed-14) coto 4

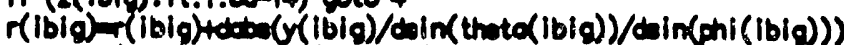

diataneer(ibig)diatenoe(ibia)-y(ibig)

xoc (Iblo) =l angth

(Ibia) $x$ (Ibla)

16

If (diataroo(ibig).10.1.01-63.and.diatanoo(ibig).90.-1.ed-es) poto

If (pla-phi(ibig). le.tartIR) than

phi (Ibig) pi-phi (ibig)

ibouncoil (ibig)mibouncal (ibig)+1

eles coto 2

andif

poto 500

andif

STI0: 2

If (phi(ibig).pe.pl2.and.phi(ibla).it.pi) then $x-\infty 00$ (ibig)

$y$ (ibig) montton(phi(ibig))

if $\mathrm{G}$ (ibig).gt.distaneo(iblg)) then Y(ibig) distones(ibig) ardif x(ibig) (ibia) $y$ (ibig)

If (z(ibig).gt.hight) goto 3

if (z (ibig).it.1.04-14) ooto 4

$r(i b i g)-r(i b i g)+(v(i b i g) / \operatorname{dan}($ thoto(ibig))/dain(phi(ibig))) diatorcos(ibig)-diateroo(ibig)-y(ibia) oox (ibia) $=4.00-14$

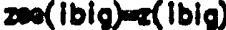

coto 180

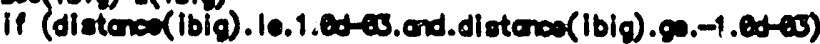

if (phi(ibig)-pi2.10.torTIR) then phi(ibig) $\rightarrow$ pl-ghi(ibig) ibouncen(ibla) =ibouncer(ibla)t1

ole poto 1

andif

coto 200

andif

If (phi(Ibig).ge.pl) goto se0

$\sin 3$

If (thote(iblg).gt.1.ed-14.and. thate(ibia). 10.pi2) then

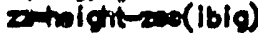

y(ibig) (zadter (thate(ibig))

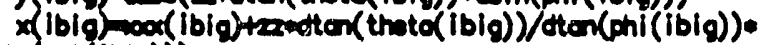
dedolin(phi(ibig))

If (r(IblQ).gt.distenoo(ibiq)) then $Y($ Ibia) distenea (ibig)

$$
\text { andlf }
$$$$
x(\text { iblg }
$$

if (x(Ibia). ot.longth) ooto i

if $(x$ (ibig).it.1.0.14) coto 2

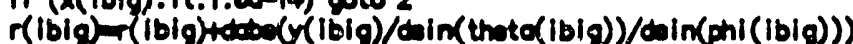

dictarded (ibig) diatanod (ibia)-x(ibia)

oor(ibig) $=$ (ibig)

2an (ibia) miolont coto 16.

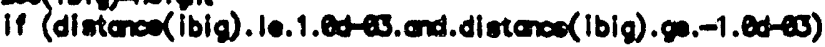

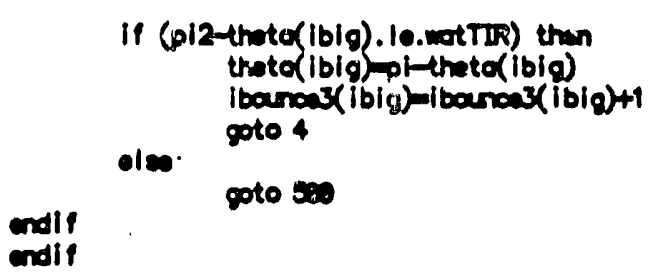


$\bullet$

$C$ teot TR ongle

C

16

70

500 if (thate(Ibig).ot.pi2.and. thate( $(\mid b i q)$. 10.pi) then zom(ibia)

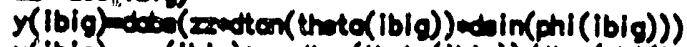

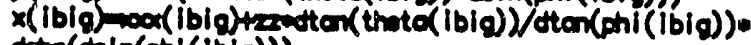
dotod(din (phi (ibia)))

if G(Ibig).gt.distenoo(ibig)) then $y$ (ibig) distonoo( $(b i q)$ andif $x$ (ibig) $\operatorname{mox}($ ibiq)ty(ibiq)/dtan(ph! (ibia))

if $(x$ (ibig).gt. Imoth) goto 1 if (x(ibio). It.1.04-14) coto 2

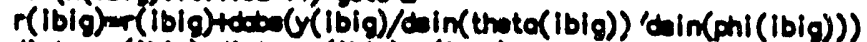
distence(ibig)-distenoe( (ibig)-y (ibig) ood (Ibig)

and (ibla) - . Qd-14

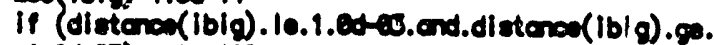

$-1.04-6)$ coto 100

if (thate (Ib/g) pi2. I0.000tTrR) then thate(ibig) $\rightarrow$ pinthote(ibig) ibounot(ibia)-lbounct(ibia)+1

ele goto 3

andif coto 500

ma flnatang pinolti

initiberneal (ibia)

12-i2tibouncee? (Ibid)

13-i3tibourcos (ibig)

istiatiberneas (Ibia)

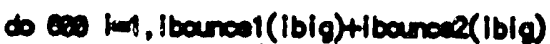
randoineren(iead) if(roftef. It.ronden) than lon rofulon reftit

contine andif coto 5

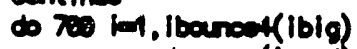
rendenman (iend) if(rofocet.lt.rondon) then lan rofulan molt coto sios

continu indif

probot dapp(rtibia)/attenuotion)

ronderieron (iread)

if (probett.1t. rodow) then

lan ot thecenctitl

andip

contine

per_producad(nurfinal it .eden)/huntot

nuntotinn finot-low rof-icen ott

por_totu(mn_tote100.00)/nuntot

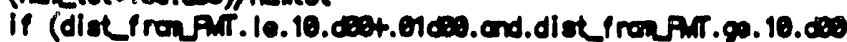
then

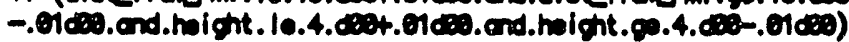

andif

$$
\text { bigper_tot }
$$

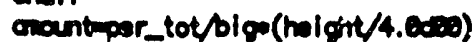

rorufooteree.ces

rtimef tof 100.00

mite $(10,101)$ cootingTIR

wite(10,

wite $(10,102)$ dist fronar

wite $(10,183)$ migit

wite $(10,184)$ lengthino.

wite $(10, \bullet)$ 


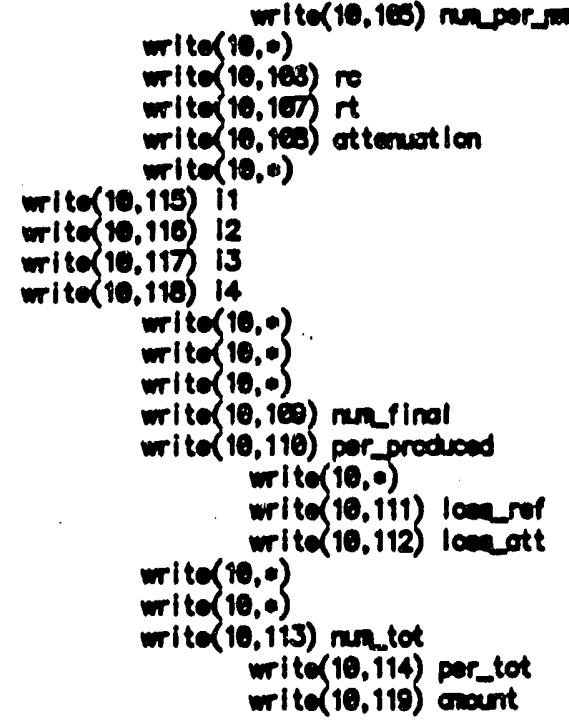

continus

formot (2x, "Sinulated doto for worple cooting with a rof lection angle:

$\cdot$ ' (8.2)

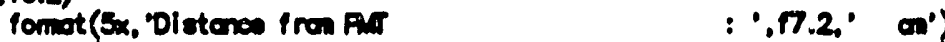

Ponsort (Sx, "Hbight of OII

formot (Ex. "Length of Dotector

$: \because 77.2,0$ in

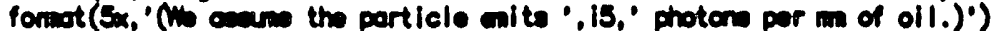

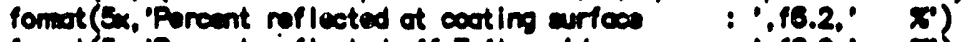

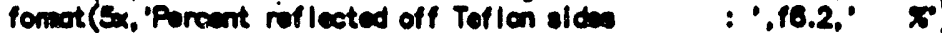

formot (Sx, 'Attenuotion Lenoth

formot (Sx. 'Final nuter of unindared photon : $: 17$ )

formot (Sx, 'Pureant frow original photor : ${ }^{\circ} 16,2, x^{\circ}$ )

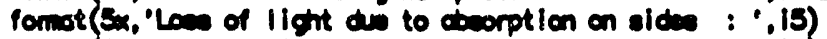

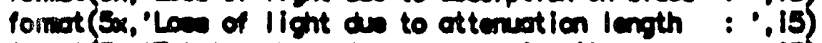

formot (5x. 'Total number of photern noking it $:{ }^{\prime}$, is)

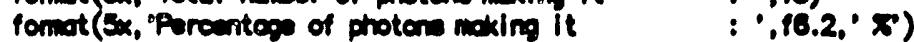

fomot (5x. "Total nuter of time photen hits Sids $1:{ }^{\prime}$, is)

fomot (Sx. 'Total nuber of times photen hits side 2 : :is)

formot (5x. "Total miber of tins photen hite voter: : is

formot (5x. "Total nutbar of time photen hito cooting : ', is)

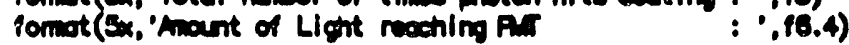

otep

and 

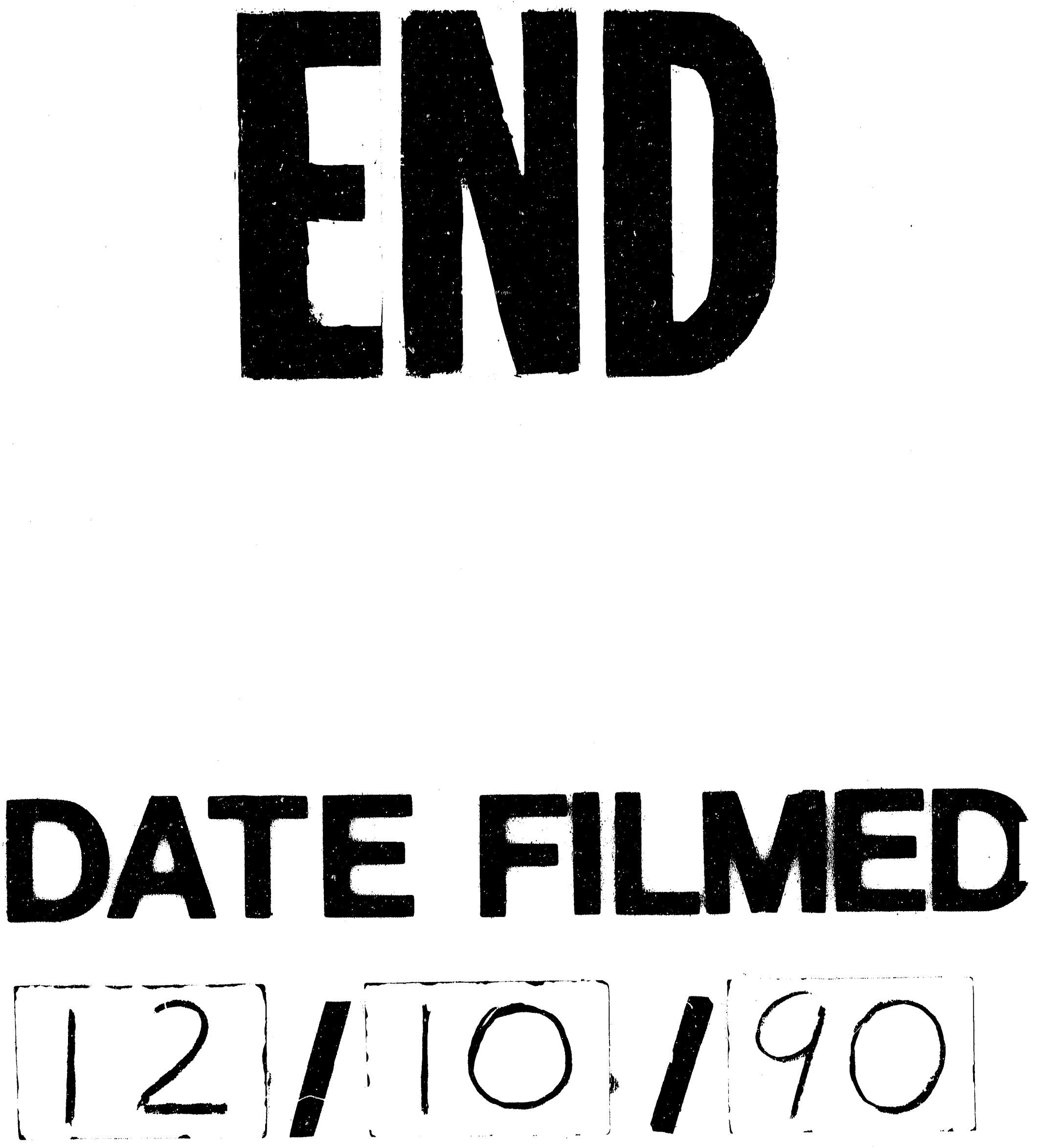
